A CONTRIBUTION TO THE

\title{
EMBRYOLOGY AND PHYLOGENY
}

OF THE

\section{PYCNOGONIDS.}

\section{A DISSER'TATION}

PRESENTED ", THE BARD OF UNIVERSITY STUDIES FOR THE: DEGREE OF DOC'TOR OF PHILOSOPHY.

BY

T. H. MORGAN,

Bruce Fellow, Johns Hopkins Iniversity.

Reprinted from Studies From the BIOJugical Laboratory, Vol. V. No. 1.

BALTIMORE :

PRESS OF ISAAC FRIEDENWALD ).

1891. 

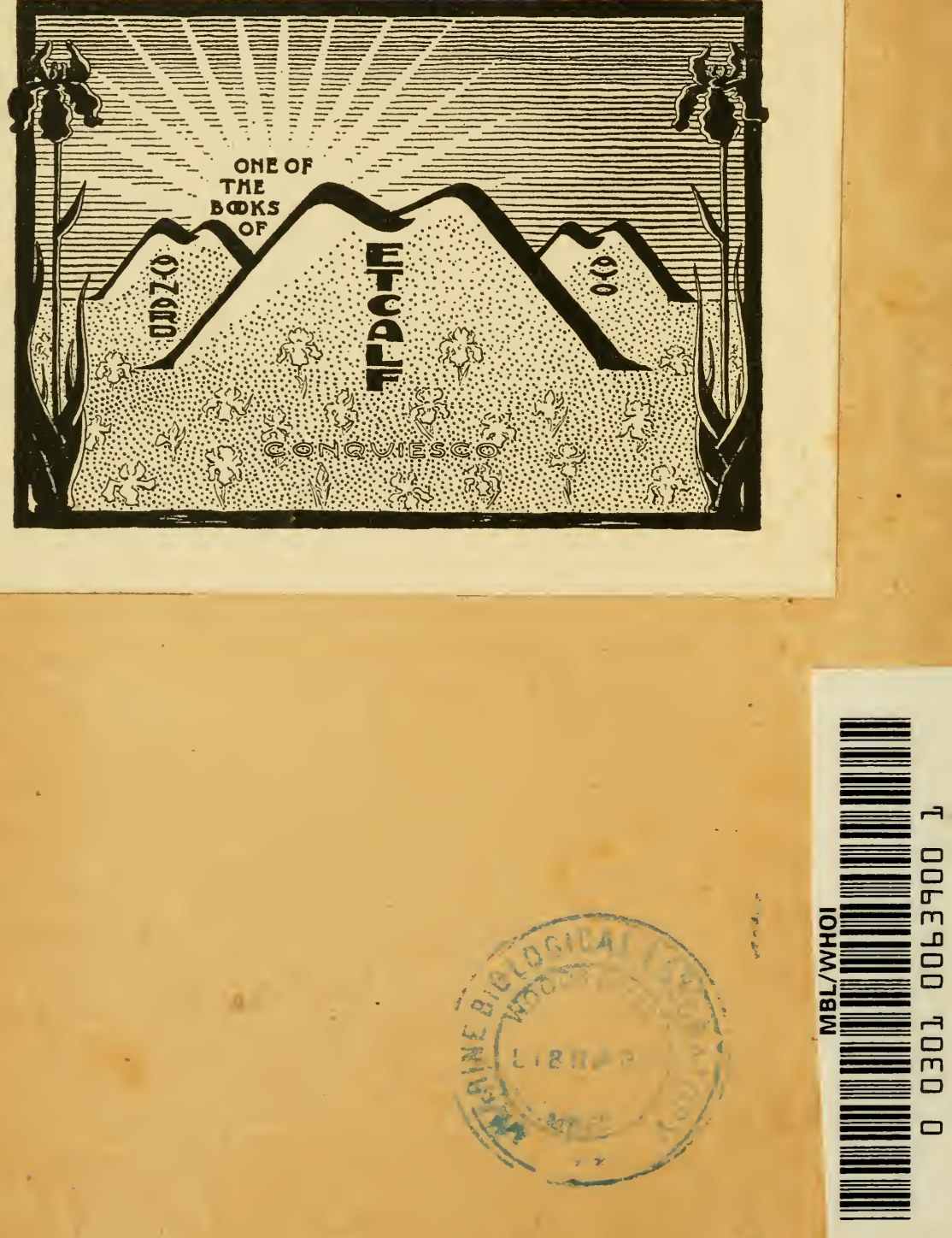


\section{A CONTRIBUTION TO THE EMBRYOLOGY AND PHYLOGENY OF THE PYCNOGONIDS. By T. H. MORGAN, Jellow of Johns Hopkins University. With Plates I, II, III, IV, V, VI, VII and VIII.}

TABLE OF CONTENTS.

$$
\text { Part I. }
$$

Introduction............................................... 1

Embryology $. \ldots \ldots \ldots \ldots \ldots \ldots \ldots \ldots \ldots \ldots \ldots \ldots \ldots \ldots \ldots \ldots, \quad 3$

Tanystylum and Phoxichilidium......................... 4

Pallene empusa.................................... 8

External changes............................ 8

Internal changes............................. 15

Comparisons.................................... 22

Phylogeny.......................................... 25

Criticism of Dohrn and Hoek......................... 25

Conclusions from Embryological Data................... 28

The "Pantopod-larva" . ............................. 33

Conclusions .................................... 34

PARt II.

The Metamorphosis of Tanystylum $\ldots \ldots \ldots \ldots \ldots \ldots \ldots \ldots \ldots \ldots \ldots \ldots \ldots \ldots \ldots \ldots, \quad 36$

PART III.

The Structure and Development of the Eyes of Pyenogonids ......... 49

The Anatomy of the Adult Eye ....................... 49

Histology of the Eye ................................ 56

The Development of the Eyes of Tanystylum .............. 59

Comparison with the Arachnid Simple Eyes ................ 63

Inversion of the Eye ................................ 65

General Consideration of the Simple Eye................. 69

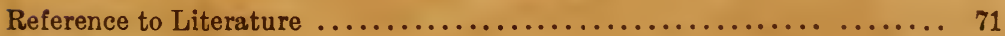

Description of Plates.................................... 72

\section{PART I.}

In the year 1767 Karl Linné, in the twelfth edition of his Systema Naturae, described under the name of Phalangium a Pycnogonid, and here for the first time is the question raised whether the group is to be ranged under the Arachnids or the Crustacea. A hundred years elapsed and the problem remained 
unsolved; the group was placed now here, now there, now amongst the Crustacea and next amongst the Arachnids. Then Prof. Dohrn attempted the solution from the standpoint of Embryology, instituting a comparison "or even identity" between the Pycnogonid larva and the Nauplius, believing the Pycnogonids to have direrged from the Crustacea at this point. During the following twenty-five years opinions once more vacillated between Arachnidan and Crustacean affinities. Recently Prof. Dohrn and Dr. Hoek have each independently monographed the group, placing the morphology of the order on a very firm basis. Independently likewise they each reached the conclusion that the group is to be placed neither with the Arachnids nor with the Crustacea, but that these three groups have come down in parallel lines.

The early stages of the embryology of the Sea-Spiders have been practically untouched, and before any final decision as to the affinities of the group is to be made, these stages in the development should be known and take equal rank with Comparative Anatomy in disentangling the relationships of the group.

For many reasons the present paper attempts in no way to give a complete answer from the embryological side. The very great difficulties of a suitable technique had slowly to be overcome, and the time at command prevented a detailed description of the different organs arising from the germ-layers, so that much remains that might be done.

In the summer of 1889 material for work was collected at Wood's Holl, Mass. Through the courtesy of Prof. MacDonald I was enabled to collect and study at the station of the U.S. Fish Commission at this place. To Prof. MacDonald I am also indebted for many other kindnesses extended during my stay at Wood's Holl. Three genera of Pycnogonids, each with a single species, are to be found at this place, viz. Pallene empusa, Phoxichilidium maxillare, Smith (Anoplodactylus lentus, Wilson), and Tanystylum orbiculare. During July, August and September these are found with eggs. Pallene inhabits the hydroids (Tubularia, Pennaria) on the piles of the wharves, and is also common on the red sea-weeds below low-tide mark. The hydroids or sea-weeds as soon as collected were brought into the laboratory and worked over piece by piece. Each bunch was 
in turn swishe̊d rapidly backward and forward in a dish containing a small amount of water, so that the Pycnogonids were shạken loose and could be easily picked out. The other genera were more easily found, and on separating the masses of hydroids, etc., could be readily seen clinging to the stems. The males of Pallene carry on each pair of ovigerous legs a small bunch of eggs. Each bunch contains from one or two to fifteen or twenty eggs. The eggs of Phoxichilidium and Tanystylum are individually much smaller than the last, but are very numerous, so that the bunches are much larger, especially so in the former. Phoxichilidium carries several bunches strung along on the ovigerous legs of the male: the bunches are white and very conspicuous against the purple color of the adult. Tanystylum has smaller bunches of eggs, with the individnal eggs larger than the former, and the masses are carried so that they form a circle of clusters held against the ventral side of the male.

The adults with eggs were put into alcoholic picro-sulphuric acid for several hours and then gradually carried through different grades of alcohol of increasing strength. Other methods of hardening gave far less satisfactory results, $i$. e. boiling water or Flemming's solution.

To prepare the eggs and embryos for study they were passed through absolute alcohol (one hour), turpentine (2-4 hours), soft paraffine (one hour), hard paraffine (1-2 hours). They were cut in paraffine, and fixed to the slide with albumen fixative; then back again through turpentine, absolnte alcohol, 95 per cent, 80 per cent, 70 per cent alcohols to Kleinenberg's hæmatoxylin, where they remain for a very long time (12-48 hours); then washed fifteen minutes in acid alcohol and up again through the alcohols to turpentine and into balsam. In Pallene each egg was in many cases pricked with a very sharp needle before going into absolute alcohol. It is necessary to do this under a dissecting microscope. By these methods very excellent results were often obtained and, after many failures of other methods, was found to be the only satisfactory one. In Pallene the larger size of the egg makes a study of the earlier stages much easier, but the other genera have a much simpler development, and it seems better to give first an account of these.

To Prof. W. K. Brooks I am greatly indebted for help and suggestions during the work. 


\section{Tanystylum and Phoxichilidium.}

The eggs of Tanystylum measure $.08 \mathrm{~mm}$. in diameter (in preserved specimens), and those of Phoxichilidium $.05 \mathrm{~mm}$. In both animals there is a regular segmentation. In Plate III, Figure $a$ is a surface view of an egg of Phoxichilidium divided into twn equal parts; in Fig. $b$ of an egg into four, but with the segments shifted around, and Fig. $c$ of an egg into eight equal parts. Similarly Figs. $d$ and $e$ for the two and four-cell stages of Tanystylum. The eight-celled stage I did not obtain for this species. Fig. $f$ is a surface view of an egg of Tanystylum at about the twenty-four-celled stage, and an optical section of an egg at this stage shows each cell to run from the periphery to the center of the egg, where they all come together at a point. Each cell is thus pyramidal in shape and contains a single nucleus.

In Plate I, Fig. 8, there is a section of an egg at a later stage than the last. This and the following sections are from eggs which were cut in paraffine. As the section is a later stage than the preceding surface view, the pyramids are narrower than before. Fig. 11 shows a somewhat older stage for Phoxichilidium. Very soon after this-perhaps after the next cleavage-a most important change takes place in the egg. I have not seen the actual change in the living eggs, but serial sections leave not the slightest doubt as to the process. Each nucleus divides radially in to two, and this is followed by division of each pyramid into two parts in a plane at right angles to the radius of the circle lying in that pyramid. This is shown by Plate I, Fig. 9, for Tanystylum. Here it is seen that by a process of multipolar delamination the egg divides into two germ-layers-an outer peripheral circle of cells and an inner mass of cells. These latter soon round off and leave no trace of the pyramidal arrangement. In Fig. 9 one cell is still seen running from the periphery to the center. This section does not show a nucleus in the inner part. The inner cells I shall speak of as the entoblast and the outer circle as the ectoblast. This figure (9) is somewhat diagrammatic, inasmuch as only part of the inner cells is shown, for usually they are more closely packed together than here shown; and in this case it is due to a part of the section having broken away (redrawn in figure) and set free some of the inner cells. In Fig. 10 is a more accurate drawing 
of an egg of Tanystylum immediately after delamination has taken place.

Exactly similar changes were seen in the eggs of Phoxichilidium, but the figures just given serve in every respect for both species. The central as well as the peripheral cells continue to divide, but soon the entoblast cells lose their well-defined boundaries and the nuclei seem in part to disappear. The result is that we have in the center of each egg a granular yolk with scattered nuclei in it. Here and there is an indication of a cell boundary. During this time the ectọblast cells hare divided tangentially and have become much smaller, yet at all times a distinct boundary remains between ectoblast and entoblast. Fig. 12 for Phoxichilidium shows an embryo at this stage.

It is here seen that the ectoblast cells over one hemisphere are somewhat higher than at the opposite, and I find this very constant in sections of both species at this stage of development. After this it becomes difficult to follow out the fate of the germlayers. The outer cells become smaller and flatter to form the ectoblast and the inner cells arranged into organs, the most conspicuous of which is the digestive tract. There is a triangular invagination to form the stomodæum, and the proboscis appears between the first pair of appendages, which has now begun to form. These appendages are very conspicuous in surface views, where they project beyond the surface of the body. Between them appears the slightly projecting proboscis, and about the middle of the embryo are seen the second and third pairs of appendages, which are small and inconspicuous. Dohrn has given excellent figures of embryos at this stage, both in his earlier paper and in his later monograph. Soon after this the egg coverings swell up somewhat and the embryos finally break out of the egg case, so that the appendages now can straighten ont.

In Plate IV, Fig. 9, is a surface view of a larva of Tanystylum as seen from the ventral surface. Dohrn speaks of this as the Pantopod-larva, and Hoek calls it a Protonymphon. Its general characters are shown in the figure. There are three pairs of appendages : the first pair chelate, with the movable claw working outwards and downwards; the second and third pairs have distally a sharp spine, in the middle of the limb a large segment, 
and proximally a prolongation of the body which is to be regarded as the basal segment of the appendage. Between the first pair of appendages the proboscis projects forwards, with the mouth opening at its distal end. Behind the base of the proboscis is seen the pair of ventral ganglia. From these the circumœsophageal commissure ascends upwards around the œsophagus, and laterally are given off on each side a pair of nerves to the second and third pairs of appendages. Dorsal to these ganglia-four in all, the two pairs being fused-is seen the outline of the mesenteron, which ends blindly behind. About the middle of the embryo and just back of the pair of ganglia is "seen a pair of oblong masses, which are the beginnings of another pair of ventral ganglia. In the basal joint of the first pair of appendages is an opaque mass composed of large cells, from which runs out a duct towards the base of the spine, and Dohrn has traced it out to the very tip of the spine, where it opens to the exterior. This organ is a gland, and its duct is the long tube in the spine.

A dorsal view of the embryo shows the brain, just above and a little in front of the ventral ganglia. On its upper surface are a pair of small pigmented eyes. A transverse section through the body of this Pantopod-larva is shown in Plate I, 13. It passes through the center of the body and cuts below the large ventral ganglionic mass, passing through the base of the third pair of appendages. Above it cuts the posterior part of the brain. In the center of the section is the digestive tract. This is cut at a point where it is about to give off diverticula to the first and third pairs of appendages. The first of these is marked $D^{I}$ and the second $D^{I I}$.

Below the digestive tract is the second pair of ganglia, which sends out nerves to the corresponding appendages. Above the digestive tract the section at $B$ cuts the posterior part of the brain. The cavity of the body has a few scattered mesoblast cells in it and a few bits of broken muscle fibers. These fibers in the living embryo served to connect the mid-gut to the bodywalls. In the base of the legs are seen several cells, which at $M$ are arranged as though around a central cavity. This cavity does not seem to connect with the mid-gut, and it seems very probable that it represents the body-cavity in the legs, and that the sur- 
rounding cells are of mesoblastic origin. In Pallene, as we shall see later, there are similar cavities, which are undoubtedly meso. blastic in origin. The mid-gut ends blindly behind, as is scen in other sections.

In Fig. 14 is shown part of a section through a more anterior part of the body. The section passes through the brain above and the first pair of ganglia below. These two are connected by the circumœsophageal ring. This commissure is composed of both cells and fibers. In the next section to the one figured a broad band of nerve fibers passes on each side from the brain to the ventral ganglia, and in Fig. 14 a few of these fibers may also be seen. In the middle of the commissure lies the cross-section * of the œesophagus. Its lumen is triangular and its walls composed of a layer of cells, which are clear around the periphery of the triangle. Around the œosophagus are a few scattered mesoblast cells. From the brain, $B$, there is part of its substance which projects ventrally towards the œsophagus and is quite conspicuous in sections of the Pantopod-larva in this region. On each side of the brain are seen a pair of diverticula of the midgut. These go to the first pair of appendages and are traceable to $D^{I}$ of Fig. 13. The first pair of appendages are, as Dohrn has shown, innervated from the brain.

The section of the embryo following Fig. 13 gives a cross-section of the pair of simple eyes. A part of this section is shown by Fig. 15. In the middle line of this section above the posterior part of the brain, $B$, the ectoblast is thickened beneath the cuticle, and immediately on each side of the middle line appear the pair of eyes. Each is seen in section to be composed of three cells-two clear outer ones with large nuclei and an inner much pigmented cell. Around the eyes the ectoblast is quite thick, and on each side it sinks down slightly from the surface, suggesting that the eye may be here increased in size.

In Fig. 16 is a section through the third pair of ventral ganglia which we saw on the ventral side of the embryo posterior to the fused pairs of first and second ganglia. The section shows that at this place the epiblast is greatly thickened and the cells columnar, with clear outer portions. In the ganglion on the left of the section the cuticle seemed to dip down into the center of the ganglion, where it becomes extremely thin. This was not 
so clearly seen on the right-hand ganglion, but traces of it were seen here also. These structures I shall speak of as the Ventral Organs; and we shall come across them again in Pallene, where they are worked out in greater detail.

\section{Pallene empusa.}

There is a great variability in the size of the eggs on the ovigerous legs of the males. The average size of those which seem to be normal eggs is $.25 \mathrm{~mm}$., but often bunches contain one or more much smaller eggs, some of which seem to begin to develop. These very small eggs are most probably immature and accidental. Although the eggs of Pallene are much larger than in the preceding animals-having 125 times the volumeyet the yolk is almost transparent, so that nuclear divisions of the segmenting egg are easily seen from the surface. The adult is remarkably transparent and consequently most difficult to see as it rests quietly amongst the hydroids or sea-weeds. It seems that the eggs have also adapted themselves for purposes of protection in thus becoming transparent. More or less time necessarily elapses after the animals are collected before they can be examined, so that I have been unable to see the extrusion of the polar bodies.

The nucleus of the egg and its accompanying protoplasm is extremely large and situated near the center of the egg. Each division of the nucleus is accompanied by a division of its surrounding protoplasm, so that in surface views it is impossible to separate the one from the other. In the figures of Plate III the darker masses in each cell indicate the position of the nucleus and protoplasm, but for the sake of brevity I shall speak of this simply as the nucleus. In the unsegmented egg the nucleus is seen to elongate and to divide into two halves, and this is immediately followed by division of the egg itself into two parts. The first furrow divides the egg into two unequal segments. Fig. $A$, Plate III, shows an egg after the first division. Each segment contains a single nucleus. (Hoek has made a different observation from this-see infra.) After this first segmentation the segments flatten somewhat and remain so during the resting period. The second division came in about three-quarters of an hour (to an hour) after the first. The 
nucleus of the smaller segment-the micromere-divided first and then the segment itself into equal parts. This was followed five minutes later by the division of the nuclei of the large segment-the macromere--and then the macromere itself.

In Fig. $B$ an egg is shown as seen from above after this second division, which is indicated by $2-2$. The planes of segmentation of the micromere and macromere are drawn in this figure as though they coincided, but this is not the rule. The plane of segmentation of the micromere may be turned at as much as $30^{\circ}$ (or exceptionally almost $45^{\circ}$ ) to that of the macromeres. I think it should nevertheless be considered as one and the same plane and one and the same division, in spite of individual variations.

The segments again flatten together, and after an interval of about an hour the third division commences. The plane of division is at right angles to the last and is shown by Fig. $C$, in which the egg is seen from above. Again the planes of micromere and macromere do not quite coincide; the numbers $2-2$ indicate the second division and $3-3$ give the plane of the present (third) division. This plane is a zigzag line lying between $3-3$. If we examine the opposite pole, the lower, of an egg at this stage, we find the large macromeres come together, as shown in $D$, although there are many differences of detail in this respect. So far the planes of division of micromere and macromere have been supposed to coincide or to be referred to the same division plane, but after this stage is reached ( 8 segments) the planes cannot be considered identical. About an hour after the last division the fourth rhythm comes on. This division plane is shown for the macromeres in side view in figure $E$, by the line $4-4$, and is seen to be parallel to the first plane of segmentation, $1-1$. The four macromeres become eight. About the same time-maybe five minutes before or after-the micromeres divide. In Fig. $E$ they are diawn after division has taken place, and Fig. $F$ shows how these cells are divided, the curved lines indicating twin cells. As we see from the very nature of the division of the macromeres, it is impossible to have their plane of division to correspond with that of the micromeres, and the division lines of the latter lie on a plane nearly at right angles to the plane of division of the micromeres. We have now eight macromeres and eight micromeres. After a resting period of about an hour the fifth rhythm begins. 
The nuclei of the macromeres of Fig. $E$ show by their elongation how they are to divide, and the plane of division lies between them or at right angles to the last division plane. Fig. $G$ shows the egg after division into eight micromeres, but the micromeres had not as yet divided and remain eight in number. Soon, however, they do divide, but no definite plane of division for all of the segments was discovered. There are now sixteen macromeres and sixteen micromeres.

The next plane of seginentation of the macromeres-at the sixth rhythm-comes in after another resting period of an hour. This is shown by Fig. $H$ at $6-6,6-6$. The two planes are at right angles to the last two $(5-5)$ and are parallel to the first and fourth $(1-1,4-4)$. I did not see the sixteen micromeres divide into thirty-two, nor could I trace them further. There are thirty-two macromeres and sixteen micromeres, or in all forty-eight cells. After an hour's interval the macromeres lying between the planes $1-1$ and $4-4$ in Fig. $H$ were each seen to have two nuclei, but this did not seem to be the case with the macromeres of the lower pole. The egg had been under observation for many hours and did not develop further, so that this last attempt at division in the upper macromeres may have no special significance.

Besides the general facts of segmentation as just given, several interesting variations in the method of segmentation of the egg were clearly made out. In the example given above the micromeres divided first (at the second segmentation), giving two micromeres and one macromere. In two other observations this was also true, but in three other cases the macromere divided five minutes before the micromere. And again in the last case the two macromeres divided into four before the two micromeres divided into four, so that the greater amount of yolk of the macromere did not seem altogether to retard segmentation. In several later stages (thirty-two macromeres and sixteen micromeres) the rhythm of macromeres and micromeres given above did not so closely correspond, but the micromeres seemed to drop behind.

If the accumulation of yolk has been a very recent event in the egg of Pallene-and the variations in size may bear this interpretation-these differences in the method of segmentation may 
be due in part to the segments of the egg struggling to give synchronous beats at each rhythm, but being hampered by the presence of the jolk. If the first plane of segmentation of Pallene corresponds with the first plane of division of Phoxichilidium and Tanystylum, and a priori this seems most probable, is it not conceivable that the acquisition of yolk to one-half of the egg might cause great changes in the synchronism of segmentation of the two parts? and if so, it is easy to imagine that we have here an egg in a period of variation, and that one or another of the above changes may become fixed for the species.

Later stages of segmentation than those described are difficult to follow or to distinguish between macromere and micromere of the upper pole, but in general the cells around the upper pole are smaller and more numerous than at the lower. Fig. $J$, Plate III, shows the ventral (or macromere) hemisphere of an egg at a later stage than any of the preceding. The outer ends of the cells, those seen in the figure, are polygonal, and the nuclei lie very near to the surface. The whole cell is pyramidal in shape, with its apex at the center of the egg and its polygonal base at the periphery of the egg, with the nuclei in the base of the pyramids. Each nucleus is still accompanied by a surrounding mass of protoplasm, and it is without doubt this protoplasm which is seen from surface views. At this time the cells of the lower pole rarely divide, and remain for a long time almost constant in size and number, but the cells at the upper pole undergo rapid changes; and our attention must now be turned almost entirely to that region.

The next change which we can see in surface views is at the upper pole, where a whitish opaque area is forming, and which may be profitably compared to the similar formation in spiders' eggs and called there the Primitive Cumulus. This is due to an accumulation of cells at this point, where an invagination is about to take place to form the stomodæum. Soon there are other opaque areas formed at the surface, which are seen to occupy definite positions and are the thickenings for the brain, ventral ganglia and appendages. These are shown in Figs. I and II, Plate IV. In Fig. I we have a surface view of the head region of a young embryo. In the upper part of the figure are first the two oval thickenings to form the brain or supra-œsophageal ganglion. 
At this stage they just touch on the middle line. Below this and on the middle line is the thickening of the stomodæal invagination. In the center is a triangular-shaped cavity - the cavity of the invagination. The base of the triangle is towards the brain. On each side are the thickenings of the first pair of appendages. In the lower part of these is a slight depression, which indicates the line between the claw and the next segment against which it works. Posterior to these various thickenings appear two rows of opaque areas, the nerve ganglia. Three pairs of these are seen in this figure, the first two being somewhat smaller than the third. On each side of the last pair appear part of the thickenings of the first pair of ambulatory legs (the fourth pair of appendages).

Fig. II is a continuation of the last figure, and shows the ventral and posterior part of the same embryo. The upper pair of ganglia are the second pair, and were seen in Fig. I, and the second pair of this is the third of the last figure. On each side of this third pair of ganglia are again the first pair of walking legs. Two more pairs of ganglia follow this third. On each side of the fourth and fifth pairs of ganglia appear the second and third pairs of walking legs. An embryo at a stage later than the last is shown by Fig. III. Here the embryo has elongated in an antero-posterior direction, so that the figure shows only the ventral side of the animal. Fig. IV is a dorsal view of an embryo at the same stage. These figures show that the region about the stomodæum has grown forward and has the opening of the stomodæum at its distal end. This outgrowth is seen in the figures as a forward prolongation of the embryo on the middle line. On each side of it are seen the first pair of appendages, which have also grown forward.

On the ventral side of the embryo appear on each side of the middle line five pairs of large ganglia (see Fig. III). On each side of the last pairs appear the three pairs of walking legs, which are longer than in the last figure, are bent, and stand out from the surface of the embryo. Posterior to the last pair of ganglia the embryo has a thickened mass of undifferentiated substance. In a dorsal view (Fig. IV) we see the brain, and behind it the large yolk mass of the embryo. The two halves of the brain have come together, and each half is slightly bi-lobed. Around 
the periphery of the yolk appear the six pairs of appendages, and behind, the thickened posterior mass of the embryo.

Returning to the ventral view of the embryo (Fig. III), there is seen a most interesting structure in the center of each ganglia. Each is an invagination of the surface into a ganglion, and these invaginations are elliptical in outline, with the long axis corresponding to that of the embryo. These structures I shall call the Ventral Organs, and, by means of serial sections, we shall later study them in more detail. In the next stage, shown by Fig. V, the embryo is more oval in outline. The appendages have also elongated and become more bent. The posterior pair have begun to grow forward between the more anterior pairs. The most important change is in the fusion of the first two pairs of ganglia, which now appear as one pair of rather large ganglia. This pair of ganglia still shows its double structure by the presence of two pairs of ventral organs. The third pair of ganglia also shows a pair of ventral organs, but the more posterior ganglia are covered by the posterior appendages, so that these ganglia cannot be seen from the surface.

After this stage is passed the appendages grow enormously in length, and the embryo becomes flattened from side to side. A figure of an embryo at this stage is shown in side view in Fig. VI. The first appendage is chelate, and has a joint near its base, and one also sees it has moved more dorsally to the proboscis. Beyond and beneath this appendage appears the proboscis, which has much elongated. Near the base of the appendage is seen part of the brain. This figure also shows that the yolk mass is continuous along the center of each ambulatory limb. The three pairs of legs are much bent, and each ends in a spine-like process. The body is seen to end behind in a knob-like projection. The ventral ganglia are shown between the bases of the legs, and the height of each at this stage is about equal to its length. In older embryos the yolk begins to disappear and the sides of the embryo to become thicker. After this the embryo lengthens a great deal, the appendages grow much longer and become segmented. Another pair of appendages appears behind the third pair of walking legs, and the knob-like projection at the end of the embryo is pushed more dorsally, to form the rudimentary abdomen. Four pairs of eye spots appear over the posterior end of the brain. 
After these changes have taken place we reach a stage shown by Figs. VII and VIII. The first figure is a ventral view of the embryo at a time when it is ready to leave the parent. The three pairs of segmented walking legs have become straightened ont at the sides of the body. In the figures only the proximal ends are shown. The fourth pair of walking legs appears at the posterior end of the body. The first pair of appendages-the cheliceræ-are now attached quite dorsally to the proboscis, which appears between and below them. Each has three segments, including the terminal one, which acts together with the second to form the pincers. On the sides of the body, just in front of the first pair of ambulatory legs, are a pair of projections, one on each side. These are the beginnings of the third pair of limbs-the ovigerous legs. I have seen no traces of the second pair of appendages in the ontogeny of Pallene. Five pairs of large ganglia lie along the body, and in addition a small sixth pair. The first pair, as we have seen, is double, and composed of the first and second pairs. The next pair, the third, is between the first pair of ambulatory legs; the fourth pair of ganglia lies between the second pair of legs; the fifth near the base of the third pair of legs, and the sixth, each of whose ganglia are smaller than those in front, at the base of the fourth pair of legs. The small, seventh pair of ganglia belongs to the rudimentary abdomen, and does not lie in a plane with the more anterior ones, but, like the sixth, is dorsal to the one in front of it, as partially shown in the figures. The osophagus is seen to start at the distal end of the proboscis and to disappear in the body, where it is not easily followed on account of its transparency. The prolongation of the mid-gut into the legs is not shown in the figures, except for the last pair of immature legs.

In Fig. VIII is a dorsal view of the same embryo. Four pairs of large ventral ganglia are seen, and in addition the small rudimentary ganglia of the abdomen. The fused first and second pairs are hidden by the brain. On the surface of the brain are seen four small pigmented eyes. The œsophagus is triangular in shape in cross-section, with the broad base turned upwards, and this base is seen from the surface. At the posterior end of the animal the rudimentary abdomen is seen, and at its end is the opening of the anus. 


\section{Internal Changes.}

Sections of the early stages of segmentation give little information in addition to what we see from surface views. They show that each nucleus is contained in a separate segment, and that many of these segments run to the center of the egg. Those cells derived from the first micromere cannot reach to the center of the sphere.

Fig. 1, Plate I, is a section of an egg at the stage when there are thirty-two micromeres. The upper part of the figure is probably in the region of the micromeres. In the center of the egg appears a clear cavity without yolk, but this is not constant for all eggs. In some it is certainly absent, but I arn unable to say whether or not it is caused by hardening reagents. What seems to be a similar cavity is found in the eggs of some spiders. The whole egg is divided up into the segments in the form of pyramids. Only some of these in this figure can be traced to the center, but other sections show each pyramid of the macromeres to have its apex at or near the center of the egg. The nuclei are situated around the periphery of the section, and the protoplasm, which invariably accompanies each nucleus, sends out fine pseudopodial filaments into the surrounding yolk.

Fig.' 2 is in the same stage as the last, and undoubtedly passes through the micromeres at the upper pole. These micromeres and their nuclei are seen to be smaller than the cells elsewhere, and the pyramids are seen to fall short of the center of the egg. There is no central cavity present in this egg.

Sections of eggs somewhat older than the last show that the nuclei of the upper pole have rapidly increased, and that they have migrated to the surface of the yolk, which loses its pyramidal structure over the upper surface. The protoplasm surrounding each nucleus comes into contact with that of surrounding nuclei, though how closely such fusion is formed I cannot say. Such a condition is shown in Fig. 3, where the protoplasm forms a cap over the upper surface of the yolk. The nuclei in this section are abnormally large, which is probably due to the hardening reagents, but the section seems normal in other respects. The lower area of the same egg shows three or four scattered nuclei near the surface of the yolk. At this stage of development there is a single layer of cells at the surface of the yolk. Between this 
stage and the next which I have figured there is a gap. In this next section, Fig. 4, we see the number of nuclei at the upper pole to be more numerous than before and much smaller. The protoplasmic cap has become larger and its protoplasm is for the most part without the amœboid processes, of the last figure.

A very important change has taken place between these two stages, viz. the formation of an inner layer of cells. Within the area of the cap appear a few somewhat flattened cells in Fig. 4, and these send out processes into the underlying yolk. Two of these cells are shown in this figure. I have not made out any definite arrangement for these cells, but they seem to lie only under the upper surface of the embryo. Where these cells come from or at what time they appear must in part be a matter of conjecture, but much light is thrown on their possible origin by a study of somewhat older stages. In Fig. 5 is a section of such a stage. The number of nuclei in the outer germ-layer has nearly doubled, and the area itself covers a much greater surface of the egg than in the last stage. Under the blastoderm are seen five inner cells with their pseudopodial extension. The larger number of these cells here than in the last figure is due in part to the greater thickness of the sections. At the lower pole are two nuclei. These belong to the outer germ-layer, although they show (as did all the outer at an earlier stage) the protoplasmic extensions into the yolk. This section itself throws little light on the cells of the inner layer, but in other sections at a similar stage I have found what seems to furnish the solution of the problem. From such sections I have drawn Figs. 6 and 7 . These are taken from the periphery of the cap of cells at some such point as $P$ in Fig. 5. Fig. 6 shows two cells which have just separated from the outer layer of cells, and we also see beyond them a single mass of protoplasm with two nuclei which presumably have just divided. I have not seen any karyokinetic figures in nuclei dividing in this direction, and it is possible we have here a direct division, as Heider has recently shown in Hydrophilus at a similar stage of development, although it is equally as possible it is due to poor preserving agents. Again, in Fig. 7, we see a single mass of protoplasm with two nuclei, the result of division. These I believe to give a clue to the origin of the inner cells of the preceding figures, and to point out that they too have had a similar origin from the outer layer. 
Keeping before us the process of delamination in Phoxichilidium, etc., I think we may regard these inner nuclei of Pallene to have come from the outer cells by delamination, and even that we may push the comparison a step farther and consider that each cell of the outer layer to have given rise at one time in its history to an inner cell, and then that the outer cells continued to divide tangentially to form the blastoderm. The reasons for such a belief are these:-In cross-section the number of inner nuclei are slightly in excess of the peripheral nuclei of the lower pole (see Figs. 4 and 5). As the outer cells of the upper pole were at the beginning more numerous than the peripheral cells of the lower pole, we ought to get, if the hypothesis be true, exactly what we do find. Further, at the periphery of the blastoderm, where the inner cells of the lower pole are added on, we can always see such a method of multiplication taking: place. The differences between this process and that in Phoxichilidium are these: that multipolar delamination does not take place simultaneously in all the cells at once, but in Pallene slowly progresses as the cap of cells makes its way to the lower pole of the egg, incorporating into itself as it goes the outer cells, which cells, as they are added on first, give off an inner cell.

After this stage we pass to older embryos, where these two layers-ectoblast and entoblast-begin to differentiate into organs. The first to appear is the stomodæum, which results from an invagination of ectoblast. This is shown by Fig. 17, Plate II. Here it is seen the ectoblast at one point has pushed inwards, and around the periphery of the invagination appear several cells with branching and anastomosing pseudopodia. These I believe to be the first appearance of the mesoblast. A few of the cells drawn in the figure belong without doubt to the entoblast, and at this stage it is difficult to separate the two. The section passes longitudinally through the embryo, and just ventral to the stomodæum there is a thickening of the ectoblast to form the first ventral ganglion. Under the ectoblast are found much branched entoblast cells, which are still comparatively few in number. Whether the circumstomodæal mesoblast comes from ectoblast or entoblast I am unable to say. Dorsal to the epiblast the epidermis continues conspicuously for a short distance and then becomes exceedingly thin. 
From this stage we pass to embryos of the age represented by Figs. I and II, Plate IV. The first figure, 18, is a cross-section through the stomodæum of Fig. I (see line 18 of the figure). The invagination is deeper than in the last section, and its lumen is closed. The ectoblast nuclei of its walls are two layers thick. On each side of this central invagination is what appears to be a lateral invagination. These supposed invaginations have given me endless trouble, and even now I feel some uncertainty as to my interpretation of them. On each side of these is seen the thickened ectoblast of the first pair of appendages. The lateral invaginations are, I believe, caused by the growth of these appendages, which tend to grow outwards as they increase in size; but are prevented from doing so by the egg coverings, and the result is that the ectoblast becomes folded on itself to make room for the growing appendages. This view is strengthened by the presence of somewhat similar invaginations at the side of the other appendages. This part which is pushed in would correspond to the dark furrow between each appendage of Fig. I and the cells forming the stomodæum. The mesoblast around the stomodæum and under the appendages has increased, and is now clearly distinguishable from the inner covering of the entoblast, which lies only at the periphery of the yolk, and between it and the mesoblast.

In Fig. 19 we have a section from the same series as the last, but more anterior and through the region of the brain corresponding to line 19 of Fig. I. The section is entirely in front of the stomodæum, and cuts the two brain thickenings of the surface view. Here again the ectoblast is seen to be distinctly folded, and this folding (invagination!) is directly continuous with the last. At first sight this seems nothing more than a forward continuation of the last groove, but it is not clear why the folding of the appendage should exert any influence over that part of the brain. Again, it might be interpreted as folding due to the brain, but I can see no good reason why such thickenings (not outgrowths) should produce the groove. There is one other possibility, viz. that these may represent invaginations into the brain itself. Against such a view is the absence in surface views of any such invaginations, and also that the folds are directly continuous with and quite similar to the groove between the stomodæum and the 
appendages, so that I cannot hold this either as a true solution. Beneath these ingrowths appears the pair of thickenings for the brain, which are seen to be continnous across the middle line. On the inner surface of these lobes are seen a few entoblast cells, as shown.

The next figure, 20, passes through the middle of the brain, but is farther forward than the last (see line 20, Fig. I, Plate III, which indicates the plane of the section). The cells of the ectoblast seem to pass into those of the brain. Sections still farther forward, where the two lobes are still cut, show the brain thickenings on each side and separated from each other. We see in surface views of embryos at this stage that the ventral ganglia have appeared, and Fig. 21 is a section through two of thesethe first pair. Not only do we see that the ectoblast has greatly thickened in two places on each side the middle line, but the outermost cells of each mass show certain peculiarities. They are much elongated at right angles to the surface, and their outer points come together at the middle point of the surface of the ganglion. The left-hand ganglion in the figure is cut through this central point, and the ganglion on the right a little to one side. The nuclei lie in the inner parts of the cells, and the outer parts of the cells are clear and transparent, while their inner ends are more granular. This difference in the parts of the cells is rery constant through the later stages. The cells form a structure which I have called the Ventral Organs.

In Fig. 22 is a section of a pair of ventral ganglia from an embryo at stage III. Here there is in the middle of each ventral ganglion a wide invagination lined by columnal cells with their clear outer portions turned towards the cavity of the invagination. The nuclei in the cells are larger than those in other parts of the ganglia, and are seen quite often in process of karyokinetic division. The spindles of the dividing nuclei are in some at right angles to the long axis of the cells, and in others parallel to the axis. A narrow connection of small ectodermal cells runs across the middle line from ganglion to ganglion.

The next figure, 23, is from an embryo at about stage $\mathrm{V}$. The outer edges of the invagination have turned in until they have nearly met above the cavity of the invagination. In other respects the section is similar to the last. 
At the next stage, shown by Fig. 24, the arching over is completed and fusion has taken place, so that there is a carity in each ganglion. The cavity does not run through the whole length of each ganglion, but lies only in its middle portion. There is no communication between the cavities of different ganglia. In this figure each ganglion has increased in size, and the cells have become more numerous, and, further, the neighboring ganglia are connected by a cross commissure of fibers. Further, the nuclei of the outer cells, those lining the cavity, are now more like the nuclei of the ganglion cells. Later stages show that the central cavity of each ganglion disappears, although they seem to persist for quite a long time after they have been enclosed by the ganglia. That this structure may have represented an organ in some ancestral form I believe possible, first, becanse it is distinctly marked, differentiated, before any invagination takes place; secondly, because their cells are histologically distinct from the surrounding ectoblast and from the cells of the ganglion beneath, and lastly, from the arrangement of the cells, which suggests a sense organ comparable to the simple ectodermal organs of many animals. It also seems probable that we have exactly similar structures in the Pantopodlarva of the other Pycnogonids.

Returning to stage III we have a cross-section of the body drawn in Fig. 25. The section passes through the middle of the body in the plane of a pair of walking legs. The large mass of yolk is still seen filling the upper part of the embryo. Over the ventral surface of the yolk the entoblast cells form a continuous covering and are indicated by $N$ in the figure. At the base of the appendage the entoblast sends ont a prolongation which is filled with yolk, while the entoblast cells are here higher and more closely packed than elsewhere. Into each of the six walking legs is a similar protrusion of entoblast from the midgut. Beyond these diverticula there is in each leg a definitely marked cavity in the mesoblast. In Fig. 25 the surrounding mesoblast is shown by $M$. As the prolongations of the mid-gut push into the legs these cavities cannot any longer be made out, and either become lost or are too complicated to follow out. Besides these cavities, which would seem to be body-cavities, we shall come to others later in development which seem to be 
schizocoels. The surrounding mesoderm of these latter is irregular and quite different from that around the body-cavity proper. The ectoderm over the appendages is thicker than elsewhere. The rentral ganglia at this stage have in most cases the ventral organs, although in this figure none are open and they have closed rather early. The ectoblast of the dorsal surface is quite thin and the mesoblast has not appeared in that part of the animal.

In Fig. 26 is a drawing of a cross-section through the head of an embryo at a stage a little later than III, but not so late as V. The section passes through the brain above and the second pair of ganglia below. Between the brain and the ventral ganglia the stomodæum is seen. Its lumen is seen to be triangular in outline, with its base turned upwards. On each side of the stomodæum appear cross-sections of the first pair of gut-diverticula. A single row of entoblast cells surrounds the central mass of yolk. Scattered mesoblast cells are found around and between these different structures, leaving here and there openings between the cells. Such schizocoels are shown by $S, S$ in the figure.

Going on to stage $V$ we find that sections give little more than was seen in the preceding figures. The prolongations of the mid-gut into the legs have grown longer, and, as seen from surface views, the first and second pairs of ganglia have fused.

In stage VI the yolk mass continues to fill the central and upper part of the embryo, but it now begins to decrease in quantity. This may be due in part to the fact that part of it becomes digested and built up into the tissue of the embryo, and in part to its extension into the legs.

A cross-section of an embryo at a stage a little older than VI, in a plane of a pair of limbs, is shown in Fig. 27. The ventral ganglia have increased enormously in size and show a large amount of punkt-substance. In the middle of the section lies the mid-gut with its contained yolk, which has decreased very much as compared with preceding stages.

In Fig. 28 is drawn a section of another embryo, at about the same stage as the last, but cuts the embryo between a pair of legs. Above the large ganglion is seen the digestive tract, which is completely separated from the body-wall by a series of 
schizocoels. The uppermost of these, lying in the middle line, is the heart, $H$. At the sides of the mid-gut appear two wellmarked cavities, and a third between the nerve ganglion and the onter wall. Also below these are two or more spaces, but these latter, and perhaps some of the others, are artefacts. The mesenteron is covered on its outer side by a distinct layer of mesoblast cells. Cross-section of some of the legs lying below the body is also shown in the figure.

Between stage VI and stage VII-VIII there is a considerable gap. During this period the embryo has lengthened and the fourth pair of walking legs has appeared. The rudimentary abdomen has been pushed up dorsally and the proctodæum invaginated until at stage VII it has opened into the mesenteron. The eyes are now seen, but at stage VI they are seen in sections as four thickenings of the epiblasts above the brain. In stage VII-VIII we find by sections that the yolk has almost completely disappeared from the digestive tract. Cross-sections also show the large nerve ganglia, the mid-gut with its diverticula, and on the dorsal part of the mid-gut the tubular heart running from the first walking leg to the third.

Fig. 29 is from a cross-section through the posterior part of the embryo and cuts the mid-gut at its juncture with the proctodæum. Below the digestive tract $D$ is a pair of small ganglia, $V^{7}$, which are the ganglia of the rudimentary abdomen. On account of the shifting of the abdomen to the dorsal side these ganglia have been carried above the last ventral ganglia, which are shown at $V^{6}$. But this is not all, for this sixth pair of ganglia has likewise been affected by the shifting of the abdomen and in turn lies above and back of the fifth pair of ganglia. In the sixth pair of ganglia, as shown in the figure, we have evident traces of the ventral organs. In the upper part of the section, and on each side of the middle line, are the diverticula of the fourth pair of walking legs. A few scattered mesoderm cells appear in the cavity of the body. The embryo must leave the male at about this time, for I have never found older embryos attached and only exceptionally ones so old as these last figured.

\section{Comparisons.}

Comparing the embryology of the two types represented by Phoxichilidium and Pallene, we find that most of the changes of 
the latter may be explained by considering it an abbreviation of the type represented by Phoxichilidium. An exact comparison of the segmentation of the two forms would be of interest; but, in order that such a comparison should be of value, the exact orientation of the segmentation plane would be essential, and such observations are wanting.

It would seem à priori most probable that the first planes in each must correspond, and that the unequal segmentation of the egg of Pallene has been caused by the greater accumulation of yolk in that part of the egg which corresponds to the macromeres. It is also probable that the smaller segments-the micromerescorrespond either to the anterior or to the ventral part of the embryo(?). Which of these is correct it is difficult to say. The embryo differentiates earlier in what corresponds to the anterior region of the adult than over the whole ventral surface, which suggests that the smaller cells may have adapted themselves to this early differentiation; but it seems equally possible that this differentiation may be due to phylogenetic laws in this particular case rather than to any mechanical connection with the micromere differentiation. So that for the present the question must remain unsettled until by actual experiment (which would not be difficult) the orientation of the segmentation planes be determined.

There is an observation on the segmentation of the egg of Pallene brevirostris by Hoek, which was mentioned in the previous description of segmentation of Pallene empusa. He says : "Le fractionnement commence par le fractionnement du noyau, et seulement aprîs que quartre noyau sont formés, un premier fractionnement devise l'oeuf en une partie plus grand et une antre beaucoup plus petite. Chaque partie contient deux noyaux qui dans le plus petit segment sont plus rapproches l'une de l'autre que dans l'autre segment."

I cannot believe this a correct observation in the light of what I have observed over and over again in Pallene empusa. There is a stage which corresponds exactly with the description, but the egg itself has previously divided into two with a single nuclens in each segment, and subsequently each of these nuclei divides into two just before the segment itself divides, and at the same time the first furrow becomes more distinct again as the 
segments round off to form the second furrow, and this seems to be the stage which Hoek has described as the first segmentation. Nor does it seem probable that the differences of our observations are due to their having been made on different species, for in each case the egg is approximately the same size.

The changes which take place in the formation of the endoderm of Pallene may, I believe, be referred to the simpler changes of Phoxichilidium, etc., and furnish in this respect an excellent basis for further comparison with other forms having much yolk present. In Phoxichilidium the pyramidal segments divide into an outer and an inner cell, while in Pallene the nuclei alone divide; and although delamination is still multipolar, it is not synchronous over the egg. A further comparison of the mesenteron I am unable to give, owing to lack of complete observations of the changes of Phoxichilidium. In both types the esophagus invaginates with a triangular lumen, and in each the proctodæum forms later in development.

The few observations I have made on the ventral organs of Tanystylum leave no doubt that it is the same structure as in Pallene. Prof. Sedgwick has described in Peripatus paired ventral organs which correspond in number and position with the pairs of ventral ganglia. Comparing Fig. 21, Plate II, with his figure for the ventral organs of the jaws of Peripatus (Studies Morph. Lab., Camb., Vol. IV, Pt. I, Plate 10, Fig. 4), a striking similarity is seen, and, in addition to this, he says in his account of the ventral organs that they are slightly invaginated from the surface. Whether these structures are in any way related it is impossible to say, but it is worth while to call attention to the close similarity both in position and structure between these organs in the two groups.

A comparison of the appendages and their order of development is of interest. Prof. Dohrn has most carefully and fully worked out the transformations of the larval forms, and through his skill we have a very thorough knowledge of the transformation of the embryo. According to his account the six-legged larvæ of the Pyenogonids with the Pantopod-development pass into the adult condition by the body elongating behind the last pair of appendages and the walking legs appearing from before backwards, in much the same way as Prof. Claus believes the 
typical Nauplius to pass into the adult. During the growth of the walking legs the second pair of appendages of the Pantopodlarva has increased a little in size, but the third pair loses its spines and the whole appendage becomes a simple prolongation of the embryo. At a later stage, when the larva has increased in size, this third pair grows out again to form the ovigerous legs. In Pallene we have seen that the first, fifth and sixth pairs of appendages appear simultaneously in the embryo. The seventh comes in very much later, and the third after the seventll. The second did not appear at all in the ontogeny, so that in the young Pallene the only appendages in the young embryo that correspond to those of the Pantopod-larva are those of the first pair. The development of Pallene has become so much abbreviated that there is only a trace of the true Pantopod-larva found in its ontogeny.

\section{Phylogeny.}

There is a general agreement that the Pyenogonids are to be placed within the large group of Arthropods, but after this there is the greatest divergence of opinion as to which group of Arthropods they are most nearly allied. In general there are two prominent categories to which all or nearly all of these theories may be referred. One lot of workers believed in a Crustacean relationship, and another lot placed the Pycnogonids amongst the Arachnids. It is needless to give here the reasons assigned for these opinions, as Prof. Dohrn has given in his monograph of the Pantopoda of the Gulf of Naples a most complete and exhaustive bibliography of the literature. The two most important views which we have at present are those of Dohrn and of Hoek, but, as the latter agrees with much that the former has given, we may consider the two together.

Prof. Dohrn's earlier view of the relationship of the Pantopodlarva to the Nauplius he has completely given up in his more recent papers. In an appendix to a paper in the Archives de Zoologie experimentale, Dr. Hoek gives a summary of Dohrn's recent theory as to the phylogenetic position of the Pycnogonids, and has at the same time contrasted his own views with Dohrn's, so that a translation of a part of this review will best bring out the resemblances and differences of their opinions. 
"For the Crustacea Dohrn rejects the Nauplius theory (of Fritz Müller and Claus) and adopts that of Hatcheck, who believes the Crustacea to have descended from parents which had the form of Phyllopods, just as these Phyllopods have in turn descended from Annelids. From these same Annelids, according to Dohrn, the Pycnogonids have come down. The number of their segments was originally more numerous than we now see them, the presence of a pair of rudimentary ganglia in connection with thể last pair of ventral ganglia allows us to add an eighth pair of appendages, and, together with the first, all of these appendages were originally homotypes. . . . They received diverticula from the intestine... and each appendage enclosed within itself a reproductive organ with a special genital opening. (The so-called excretory organs of the palps and of the ovigerous legs are the rudimentary sexual organs of these appendages.) The appendages were much shorter than we now see them, the heart showed many openings, etc. The supposed ancestor that Dohrn reconstructs might be very well compared to an Annelid. "We also notice that Dohrn persists in his opinion, published in his work of 1879, that the Pycnogonids have a parentage neither with the Arachnids nor with the Crustacea (they have developed by the side of the last and altogether independently). In this I am in accordance with Dohrn. I was struck in the first place by the very general presence in the Pycnogonids of a characteristic larval form (the Protonymphon), and its presence suggested to me the idea of their descent from an ancestor resembling somewhat a larva which took its place by the side of the hypothetical ancestor of the Crustacea-the Nauplius-and this by the side of a third (the ancestor of the Annelids), and that all three groups would have descended from a common ancestor. I had tried to obtain in this way an explanation of the affinities of the three groups of animals (Annelids, Pycnogonids, Crustacea). Dohrn, on the contrary, took into account the larval forms, but constructed a phylogeny comparing together those animals having a considerable number of segments. It is true I do not wish to deny that such a method of looking at it has not just as good a basis of reason, only it appears to me at present that it can be defended just as little, and certainly no better than the larval theory. 
"No one affirms that the intestinal diverticula which now in Phoxichilidium and Nymphon penetrate into the proboscis were originally [ancestrally] in the palps and ovigerous legs. The homology of the glandular organs of appendages II and III with parts of the sexual organs is not based on any observation. . . . But since I believe there are certain things which lessen Dohrn's arguments in favor of the Annelid theory, I believe that at bottom and the contents of pages $52-115$ of his work confirms this opinion, the ideas of this anthor and of mine upon the phylogeny as well for the Crustacea as for the Pycnogonids are not very different. At first I saw only the weak side of Dohrn's theory, that he does not give any explanation of the almost universal presence in the ontogeny of these animals of a characteristic larval form (thelarval Protonymphon, which for myself is a true primary larva in the sense of Balfour). So that I cannot adopt a theory which causes to arise a form of Arthropods with inany segments from an Annelid with the same number of appendages; but such is not the opinion of Dohrn, as clearly expressed in the following paragraph: "Thus the larva of the greater part of the Pycnogonids may be regarded, with a grain of salt, as a form much like the ancestor; but if, on the other hand, the absence of an anal opening, the pincers of the first pair of appendages, the long claws with their accessory spines, the structure of the proboscis with its triturating apparatus and its ganglia, and the form of the cutaneous glands with their integumentary hairs, can only be considered as having been acquired in a much later stage, and transmitted to larval life where they are found at present; but what remains in the larva that we may regard in reality as inherited from its original condition? Nothing but the nervous system, $i . e$. the brain and ganglia, an intestine, three pairs of appendages of a form modified according to circumstances, and two eyes! But these are attributes which one finds equally in the larva of Annelids with three segments! And if then we take into consideration that at one time the body of the Pycnogonids, as we believe, showed a great nniformity in the segments (and the generative organs prove this), that on the one hand there was a concentration and a differentiation, and on the other hand a reduction in number of segments, these two conclusions lead us to admit a direct descent of the Pycnogonids from ancestral 
Annelid forms which were homonomously segmented. Then the larva of the Pantopods came from a larval form with Pantapod characters added on, but at the same time a larva which never had an independent and mature existence." "

Whatever Hoek's position may be with respect to the Pantopod-larva, he agrees with Dohrn in the most important part of the latter's theory that the Pyenogonids have come down from the Annelids independently of the other groups of Arthropods. In examining the preceding account we may take it up for the sake of clearness in two parts, the first pertaining to the ancestry of the adults, leaving the larval form out of account, and the second part where the meaning of the larval form will be considered.

I believe that if the account I have given of the early stages of development be even approximately correct, there is little or no ground for a comparison between Crustacea and Pycnogonids-certainly not with any existing forms. The multipolar delamination of the endoderm in the Pycnogonids has no homologue amongst the Crustacea, nor is there any special similarity in the formation of the organs. There seems to be no trace of gastrulation like the Crustacean in the ontogeny of the group. And if we have reason for rejecting a relationship between the Pantopod-larva and the Nauplius-and I believe with Dohrn that we have-there remains nothing in common to the ontogeny of the two groups.

Nor are there any special affinities between the Insects and Sea-Spiders, but there is one striking similarity between the latter and Peripatus, which I have already spoken of; but an isolated fact of this kind gives little ground for further comparisons. The ventral organs in the two groups present a striking agreement, but there is no proof forthcoming as to a real homology of the structures. The process of the formation of the endoderm described by Heider and by Wheeler in Insects shows a certain resemblance to multipolar delamination, but if it be such it is a more complicated form than shown by the Pycnogonids. With these two exceptions there seems to be nothing else in common in the ontogeny.

We are then left to decide between an independent origin for the Pycnogonids or a relationship with the Arachnids. Prof. 
Dohrn has ably maintained the first theory, and the preceding translation gave the conclusion he had reached. Dr. Hoek likewise, as we have seen, holds this opinion, although not agreeing as to details with Prof. Dohrn. On the other hand, a study of the early stages of the embryology has brought to light certain facts which for me point decidedly toward a community of descent between Arachnids and Pycnogonids. The latter show undoubted traces of degeneration, and we cannot derive them from any existing animals. But I believe the Pycnogonids and the Arachnids have come down along the same line, or, in other words, have had ancestors in common long after those ancestors came from Annelid-like forefathers. The reasons for such a belief are as follows:

1. The Pycnogonids form the endoderm by a process of multipolar delamination, which is shown in its simplest form in Phoxichilidiurn and Tanystylum, and in a more modified condition in Pallene. In no other group of the Triploblastica do we find a similar phenomenon except in the Arachnids. The description of the embryology of Chelifer which Metchnikoff has given shows this process or something quite analogous to take place in it. The segmentation is holoblastic, and at a later stage the large cells containing yolk divide into an outer, more protoplasmic layer of cells and the inner cells, which are very granular. The outer form the ectoblast, and most probably the inner, judging from his figures, form the entoblast.

In the Spiders the process is not so well marked, but if the conception which Balfour had of the formation of the yolknuclei be true, then we may make a direct comparison between the two groups. He says: "It appears to me probable that at the time when the superficial layer of protoplasm is segmented off from the yolk below the nuclei undergo division, and that a nucleus with surrounding protoplasm is left with each yolk column." This description for the Spiders may be substituted, word for word, for the process of delamination of Pallene.

2. The first trace of the embryo to appear in Pallene is a round opaque area at the spot where the stomodæum invaginates. In Schimkewitsch's recent account for the Spiders he shows that the primitive cumulus in them is the place where the stomodæum invaginates. This is also true for Pallene, but here 
the stomodæum invaginates quite early and perhaps simultaneously with the early formation of mesoblast at this place. Further, Schimkewitsch has called attention to the fact that the stomodæum of Spiders in its earliest development is a triangular invagination, and he compares it directly with the triangular invagination of the œsophagus of the Pycnogonids.

3. The early formation of body-cavity surrounded by mesoblast in the legs of Spiders has an exact parallel in Pallene and Phoxichilidium. Yet, however tempting such a comparison may be in this connection, it must be admitted I have not conclusively proved this to be true for the Pycnogonids, but only exceedingly probable.

4. In both Arachnids and Pycnogonids we have well-marked diverticula from the mid-gut into the legs. In the Pycnogonids these go into the cheliceræ and the four pairs of walking legs, and the same holds for the Spiders; but from a comparison of the appendages of the two groups we must suppose that the second pair of Pyenogonid's appendages to have lost their diverticula, and the last appendages either to have acquired diverticula, or more probably inherited them together with the appendage. In Chelifer the diverticula appear very early in development and contain some of the yolk from the mid-gut. This is shown very distinctly in Metchnikoff's figures for Chelifer, and in this respect the embryo resembles closely the embryos of Pycnogonids.

5. In both Arachnids and Pycnogonids the first pair of appendages are chelate. This in itself would draw attention to the similarities of the two groups, but we know further that in both groups this first pair of chelate appendages is innervated from the brain. These facts were considered by Balfour sufficiently important to indicate alone a relationship between the groups. He says: "The presence of chelate appendages innervated in the adult by the supra œsophageal ganglia rather points to a common Phylum for the I'ycnogonida and Arachnida, though, as shown above, all the appendages in the embryos of true Arachnida are innervated by post-oral ganglia."

I have not been able to find any post-oral ganglia for Pallene, but the first pair of appendages arises on the sides of the stomodæum and later moves forward. In this respect it compares closely with the Spiders, and the early innervation of this pair 
from the brain itself may be regarded as a more abbreviated condition than what was seen (by Balfour) in the Spiders. Metchnikoff's figures for Chelifer show the first pair of appendages to arise above and on each side of the proboscis-like upper lip. If future work verifies Metchnikoff's suggestion that this proboscis (rüsselformige, provisorische Oberlippe) is homologous, entirely or in part, to the proboscis of the Pycnogonids, as his figure might indicate, then does the whole development of Chelifer show remarkably close resemblances to the Pycnogonids.

6. The fourth pair of ambulatory legs-the seventh pair of appendages-has been a stumbling block in the way of those who have compared Pycnogonid with Arachnid. Semper and Schimkewitsch have attemped to solve the difficulty by assuming that the third pair of appendages of the Pycnogonids-the ovigerous legs-are new structures, and then have called the four pairs of walking legs homologous in the two groups. Prof. Dohrn has shown the impossibility of dropping out in the count the ovigerous legs, and has shown that this pair of appendages are homonomons with the others. The two pairs of ventral organs in the anterior larval ganglia we have seen point unmistakably to the same conclusion and give the final proof, if such were really necessary.

We are led then to a comparison of the appendages of the two groups, beginning with the cheliceræ and going back pair for pair, which leaves one pair over for the Pycnogonids. Any comparison between the two groups must take into account this extra pair of legs. Balfour has suggested that this last segment and its appendages to represent the first abdominal segment of the Arachnids. The third pair of appendages of the Pyenogonids have assumed a special function, and at this time we might suppose that an additional pair to have been added on from the abdominal segments. We also know that the embryos of Spiders have rudimentary appendages on the abdomen, and, as we have assumed the Pycnogonids to have come from the latter group, not recently but remotely, when these appendages may have been larger or even functional, we have some ground for a belief of such an origin of the last segment.

There is another fact which may be of importance in this connection. Not only is the seventh pair of ganglia carried dorsal- 
wards by the abdomen, but at the same time the sixth pair of ganglia also is carried dorsalwards and above the fifth pair, from which the connecting nerve fibers pass upwards to the sixth. At the present time it is impossible to determine whether this is due to a mechanical adjustment between the shifted abdomen and the last pair of thoracic ganglia, or whether the sixth pair, belonging properly to the abdomen, has taken part in the general shifting of that structure. ${ }^{1}$

There are certain objections against this comparison which I have attempted, and if they do not directly oppose yet do not support the hypothesis. First and most important is the uncertainty of brain invaginations in Pycnogonids. These seem to be present in all the Arachnids, and easily seen in the development of the embryo. In the Pycnogonids I have not been able to find such invaginations. We have seen in Fig. 19 that the groove might possibly bear such an interpretation; but even if this were true, we would expect to find a much more pronounced involution, but this does not seem to be the case. Again, the ventral organs, which have been compared with those of Peripatus, lend nosupport to the hypothesis. It is possible that the Pycnogonids have come from the Arachnids, at a time when these latter have had such organs in common with the ancestors of the Insects, and that they have been fully retained in the Pycnogonids. Lastly, the openings of the reproductive organs. Typically the ovaries and testes of the Sea-Spiders are a pair of organs united posteriorly by a cross commissure. They extend into the walking legs and open on the second joint of these. There are many exceptions to this, but they are regarded as secondary. The openings on the legs have no homologue in the Arachnids, except perhaps in Limulus, nor does it furnish any ground for comparison with other Arthropods. But if we assume the group to have come directly from the Annelids, we have no better ground here for a comparison. We are greatly in need of observations on the development of the sexual openings, and until we get such, the

${ }^{1}$ If we assume with Hatchek a common descent for all Arthropods, and that in the Insects we have several of the anterior segments about the mouth, suppressed, we might assume that the Spiders have lost a third pair of appendages, and the Pycnogonids retained it, and in this way bring into line the other appendages of the groups. 
question must remain an open one. It seems not improbable, however, that the openings may be secondary and connected in some way with the secondary presence of reproductive organs in the appendages.

I hope to have shown that these three objections are of negative value, at any rate so long as the present uncertainty surrounds them, and that we have sufficient grounds for a comparison in the early stages of development and in some of the important adult structures of the two groups.

\section{The Pantopod-Larva.}

There is a general resemblance between the Nauplins of the Crustacea and the larva of the Pycnogonids, but the differences become greater and greater the more closely we examine the two forms. In each the body contains three pairs of appendages, but those in the Nauplins show biramous structures, while none of the Pantopod-larval appendages show such structures. Moreover, the first pair of appendages of the Pantopod-larva is chelate and innervated from the brain. Other characteristics of the larva are the well-marked proboscis with its triangular œsophagus, the mid-gut sending out prolongations into some of the appendages, and the absence of any anal opening.

Have we then any basis for the assumption that this Pantopodlarva is a modified Trochophore of the Annelid ancestors? The problem is very similar to that of a supposed relationship between the Nauplius and the Trochophore, and in both cases an answer exceedingly difficult to give. Prof. Dohrn believes that the Pantopod-larva is to be regarded as a Trochophore with the Pyenogonid characteristics reflected back upon it. Prof. Lang believes in a similar process for the Nauplins. Without discussing the latter, let us confine our attention to the possibilities of the Pantopod-larva.

What characters have been "reflected" on Dohrn's theory, and what remains after these are removed? Prof. Dohrn has given us the answer. "... The absence of an anal opening, the pincers of the first pair of appendages, the long claws with the accessory spine, the structure of the proboscis with its triturating apparatus and its ganglia, the form of the tegumentary glands and their characteristic hairs, can only be considered as having been 
acquired in a much later stage and transmitted to larval life." That is to say, that almost every characteristic of the larva has been handed back from the adult! And what remains? "Nothing but the nervous system ... an intestine, three pairs of appendages and two eyes." "But these are the attributes which one finds equally in the larra of Annelids!"

There is one vital fact which has been left out of account, viz. the presence of an anus in the Trochophore. How can we account for its absence on the above hypothesis when we know the Pantopod-larva to be a free-living larval form? And unless some special reason for such a loss can be imagined, the very basis of the comparison between Pantopod-larva and Trochophore is gone! What we have done in the above process of subtraction is to have removed the most striking structures of the adult from the larva and have left, not a Trochophore, but only the framework of the Pycnogonid.

For two main reasons I am unable to believe in the phylogeny given by Dohrn or by Hoek. First, because it seems to me there are facts derived from the early stages of development which point unmistakabiy to a relationship between Pycnogonids and Arachnids; and in the second place I cannot believe any actual homology to exist between the Pantopod-larva and the Trochophore, nor any fair reasons to assume that the characteristics of the Pycnogonids have been reflected upon a 'Trochophore.

If, then, we start with the assimption that there is a relationship between the Sea-Spiders and Arachnids, we may examine into the meaning of the larval form as a corollary to such a position.

I have stated that the Pycnogonids are degenerate, and probably not derivable directly from any existing group. If so, how far down in the ancestral tree of the Arachnids have they arisen? The very great differences in the adult structure of the groups indicate no very recent origin, but possibly they came in at a time when the Arachnids had the first pair of appendages chelate, and these were innervated from the supra-œsophageal ganglia, and had coeca from the digestive tract into most or all of the appendages. After the divergence of the Pycnogonids as a group from the general phylum of the Arachnids, the Pantopod-larva may have developed.

The Pycnogonids have adapted themselves to a very special 
habitat, and in general, what we may suppose to have happened, was a decrease in the size and an increase in the number of eggs, with the resulting early development of the free larva that we find to-day. This larva represents the more anterior segments of the adult, viz. that part containing the proboscis, the œosophagus, the eyes, the chelae, and two post-oral appendages. Behind this is an undeveloped part, which slowly grows in length as the animal increases in size. The anus belongs to the last segment, and does not appear until that segment is wholly or in part developed.

If the Arachnids have come from Annelid ancestors with many segments, we have a clue to the slight resemblance between the Pantopod and the Trochophore. The former represents the most anterior segments of the adult Sea-Spiders, and therefore to some extent the anterior segments of the Annelids or of the Trochophore. But at no time in the ontogeny of the Pycnogonids have Trochophore and Pantopod-larva been transformed the one into the other, as Dohrn believes.

Such seems to me the more probable view of the meaning of the Pantopod-larva. This belief has grown out of my work on the embryology of the group, and whether future work supports or disproves such an hypothesis, it is hoped it may be useful, if oniy as furnishing another point of view for looking at the phylogeny of the Pyenogonids, or may lead to a more complete study of the embryology of the group. 


\section{PART II.-THE METAMORPHOSIS OF TANYSTYLUM.}

The material for the second and third parts of the present account was collected during the summer of 1890 , while at the Marine Biological Laboratory at Wood's Holl, Mass. I wish to express my gratitude to the Director, Prof. C. O. Whitman, and to the trustees of the laboratory, for the opportunity to carry on investigations under the favorable conditions offered at the marine station.

My object in giving the figures and description of the metamorphosis of Tanystylum is, in the first place, because I was fortunate enough to obtain probably a complete series of the larval stages of this Pycnogonid, and inasmuch as the remarkable condition of the development, and adult condition of the appendages of the Pycnogonids, offer in themselves a most interesting field for study, I hope a contribution to the complete metamorphosis of one form may be found useful. Again, by means of serial sections of each of these stages, I hope to have added a little to our knowledge of the internal changes taking place during development, as heretofore we have had only such knowledge as could be gained hy surface views. Lastly, the figures give a series to which intelligible reference may be made when speaking in Part III of the Development of the Eye.

Not much difficulty was experienced in getting excellent sections of the embryo during its metamorphasis. As described in Part I, the embryos were killed in alcoholic picro-sulphuric solution (35 per cent alcohol saturated with picric acid, to which the usual amount of sulphuric acid was added). Before staining, the appendages were cut off (only possible, however, in the later stages) and the body stained overnight in hæmatoxylin; afterwards embedded in paraffine and cut into sections, which are better if cut so thick as 10 to $15 \mu$. The figures on Plate V were all drawn to scale, showing the enormous increase of growth during larval life. Figs. XXV and XXVI of Plate VI were also drawn to the same scale.

I cannot be sure that the series of figures drawn on Plate $\mathrm{V}$ and Figs. XIX, XX, XXI on Plate VI give the perfectly com- 
plete metamorphosis, although I believe the set must be almost filled out especially for the later stages. Here I could procure great numbers of individuals, and, comparing them and finding no intermediate stages, I inferred none such existed. But in the very young stages, before the appearance of the first pair of walking legs, it is extremely difficult to know how complete the series is; but from the slight gradations in size and structures in those figured, I think we shall not be far wrong in assuming an almost or entirely complete series.

In Part I of the present paper I have figured and described at length the structures of the Pantopod-larva of Tanystylum at the time when it leaves the parent. I shall speak of an embryo of this age as stage 1 (see Plate IV, Fig. IX). In examining the hydroids for Sea-Spiders, I found one embryo a little larger in size than this first stage, and having other slight differences which plainly show it to be a stage in advance of the last, and probably a stage immediately following stage 1, or after the first larval skin is shed. Figures of this stage (2) are seen in $\mathrm{X}$ and XI of Plate V, showing the ventral and dorsal views respectively. The embryo has much the same shape as stage 1 , but there is seen an important difference between the two stages. The older larva has the posterior part of its body filled with a solid lobed mass of cells, which contrasts strongly with the clear posterior part of stage 1. Further, the second pair (really the third, as the first is double) of ventral ganglia are much larger. The posterior pair of lobes of the mid-gut project to the sides of the embryo, and an examination of the periphery of the posterior border shows a slight indentation on each side, indicating the beginning of another pair of appendages. The first pair of appendages, the mandibles, are three-jointed, and have, projecting forward from the first, proximal joint, a strong spine, as in stage 1 . The second and third appendages are each two-jointed, with a strong terminal, movable spine. The proboscis lies in the mid-ventral line, and projects forward between and ventral to the first pair of appendages. Fig. XI shows the dorsal view of the same embryo. From the figure we see that the digestive tract of the embryo is on each side three-lobed. The first pair of lobes projects into the first pair of appendages, the second pair of pouches towards the base of the third pair of appendages, and the third 
pair of pouches projects into that portion of the posterior part of the embryo from which the next pair of appendages arises. In the anterior dorsal part of the larva are seen the first traces of a pair of eyes; the first pair of appendages is bent towards the ventral surface.

This embryo was stained and cut, and from the series of sections the following facts obtained: There is a small brain connected by means of a pair of commissures with the anterior ventral ganglion. This first ventral ganglion is, as we saw in the earlier larva (Part I), really a pair of fused ganglia. Behind this lies the second ganglion (the third of the series). The œsophagus, running back from the mouth through the proboscis, opens into the mid-gut. The latter has a pair of prolongations into the base of the first pair of appendages, and another pair of pouches run to the base of the third pair of appendages. The posterior part of the larva contains a backward continuation of the digestive tract, which seems still to end blindly behind. The cells lining the wall of the gut are now quite different from those observed in stage 1, which were seen in Fig. 13, Plate 1. In the present stage (2) they are much larger, are filled with large round masses of yolk-like substance, so that the lumen of the gut is almost obliterated. The yolk-like substance must have come from the exterior, and indicates that the animal is feeding at this stage and, perhaps, is supplied with abundance of food-material. No solid extraneous matter was ever seen in the tract of either larvæ or adults of Sea-Spiders, so that the food is probably obtained by sucking the juices of other animals-another similarity to Arachnids!- -and probably from the hydroids, amongst which they live. The series of sections did not show any traces of a heart. A single pair of eyes was seen over the brain, and to the sides of these a thickened mass of ectodermal cells.

Passing to what seems to be the next stage of development, we have an embryo, shown by Fig. XII, Plate V, stage 3. There is quite an increase in size, especially marked in the length of the embryo. The first pair of appendages and the proboscis are longer and larger than in the last. The second and third pairs are as in the preceding stage; but the embryo now shows clearly external indications of a fourth pair of appendages. The preserved larva was quite opaque, and nothing of the 
internal organs could be made out from the surface, so that sections were again resorted to. Here it was found that the midgut gave off the usual diverticulæ to the first and third pairs of appendages and, besides, quite a large pair of pouches into the undeveloped fourth pair of appendages. The sections show that the gut ends blindly behind, and no trace of proctodæum was found. The lumen of the digestive tract is almost entirely obliterated by the large size of the cells, and these are completely filled with spherules of yolk. Large, active ectoblast and mesoblast cells, together with the mid-gut, fill up the posterior part of the embryo. The fourth pair of appendages is quite far advanced, as the ectoblast, by pushing in from behind, has partitioned off on each side a part of the posterior part of the body. The ingrow th of ectoderm on each side is always two-layered, furnishing a new wall to the outer sides of the body and to the inner side of each new leg. The first (double) pair of ventral ganglia is followed by a well-developed second pair, each containing large cavities, and these are followed by a smaller fourth pair of ganglia. There is a single pair of eyes.

The next embryo which I have found shows a considerable increase in size, and I cannot be certain that it is the stage following the last. Still it is probable, as I have found five or six of this size and none in between this and the last. The larva is shown by Figs. XIII and XIV giving the ventral and dorsal views of this stage (4th). The most marked external change is in the great elongation of the body posterior to the third pair of appendages, and in this region we can distinguish a central middle lobe and a pair of lobes on either side of this closely pressed against the middle part, the side lobes being the ' anlage' of the fourth pair of appendages. Three pairs of ventral ganglia were made out from surface views, but sections show also a small forming fourth pair. The embryo shown by Fig. XIV is the same, but from dorsal view. It shows a slight constriction in the middle of the body at the base of the fourth pair of appendages, and the continuation of the body posteriorly between these appendages is seen to be broader than the same region on the ventral surface; and further the base of the middle posterior lobe suddenly widens out, as seen in the figure. A single pair of eyes is shown on the anterior dorsal surface. Sections of this 
embryo give these points: The third pair of ganglia still have large cavities and a small fourth pair is in process of formation. The mid-gut sends the usual diverticulæ to the first and third pairs of appendages, also quite a large pair of pouches to the fourth appendages, and lastly a short pair, in the region of the third ganglia, runs out at right angles to the gut. These last pouches pass into that part of the embryo corresponding to the sudden widening at the base of the middle posterior lobe. Sections show that at this place the ectoblast pushes into the body cavity from behind forwards, forming partitions which are the beginnings of a new pair-the fifth pair-of appendages. Posteriorly the mid-gut seems to be continuous with a proctodæum which, I think, forms at this stage. It also seems probable that the heart forms at this stage of development, but the sections I have do not speak definitely on this point. I could not discover any trace, as yet, of reproductive organs.

We come now to a stage which, I suppose on account of its larger size, is easily found and not at all uncommon. I think it is undoubtedly the stage formed immediately after the moulting of stage 4. The small undeveloped fourth legs of stage 4 have now, in stage 5, Fig. XV, spread out laterally after the shedding of the cuticle, and have become segmented. The whole larva is longer than in the last stage, and all the external organs are also comparatively larger-the appendages, the proboscis, and especially the posterior part of the body. The most marked change is in the addition of the large fourth pair of appendages - the first pair of walking legs of the adult. Each of these is at this stage composed of six segments, of which the first three are somewhat smaller than the following four distal segments. The fourth segment of each limb, counting outwards from the body, shows internally traces of division into two parts, although the chitin covering the ectoblast is not divided. The spines projecting from the three distal segments of the legs must assist greatly in clinging to the hydroids, and particularly the long terminal hook with its two side hooks. Five pairs of ventral ganglia are seen from the surface-the first, as we know, being composed of two pairs. Other differences are easily gathered from the figure. Sections show that the digestive tract opens posteriorly to the exterior by means of a proctodæum. The first 
pair of diverticula from the gut runs forward into the limb as far as the glands of the mandibles, which are still retained.

Where these pouches join the digestive tract a second pair of diverticula originate and passes to the base of the third pair of appendages. A large pair of diverticula run out in to the penultimate segment of the fourth pair of appendages, and behind these is a pair of pouches, the fourth, into the fifth pair of appendages, and, lastly, traces of a fifth pair of pouches is found. In Plate VIII, Fig. 52, there is a cross-section through the posterior part of this larva. It passes through the fifth pair of appendages, which are still at the sides of the body, and below the section passes through a pair of small forming ganglia. This section shows the thick ectoblast, the scattered mesoblast cells, especially abundant in the legs, and the large endodermal cells filled with food particles. On each side of the ventral ganglia are two other invaginations of the ectoderm. These push in both above (not seen in this section) and below and from behind -forwards as well, and form a partition wall in the body cavity, which cuts off a pair of appendages. The invagination for the ventral ganglia, shown in the figure on each side of the ventral median line, are the ingrowths for the fifth and last pair of body ganglia. There is a distinct proctodæum opening behind. In a single section of this series I found a well-marked ' anlage' of the sexual organs. It was on the dorsal surface of the digestive tract, in the middle line, and in that part of the body corresponding to the base of the first pair of walking legs. It was thickest in the middle, and tapered away towards the sides of the larva, but was confined entirely to the body. Dorsal to this mass of cells of the reproductive organ was what seemed to be an accumulation of blood corpuscles, and I fancied I could rake out traces of a large heart cavity. In another embryo of the same age as the last I could find no traces of reproductive organs. There are four eyes on the dorsal surface, and the first pair are nearer together than the posterior pair, and on each side of the first pair there is a thickened mass of ectoblast cells. We saw there were five pairs of ventral ganglia, and it is worthy of note that the embryo with a single pair of walking legs has formed the 'anlage' of all the other ventral ganglia to the appendages.

In stage 6 , represented by Fig. XVI, we find a second pair 
of walking legs, and, moreover, the embryo has increased a great deal in size. The first three pairs of appendages are essentially as in the last stage. The fourth pair has now acquired its adult number of segments, viz. eight. The two new segments which have been added were interposed, the one between the fifth and sixth (distal) of the preceding stage, and the other in the middle of the fourth pair, in which we saw faint internal traces of division in the last stage. The newly acquired fifth pair has now six segments, three smaller proximal ones and three distal.

In the posterior part of the animal the undeveloped sixth pair of appendages appears on each side of the body, and in between the bases of these appendages appear the small 'anlage' of a seventh pair. Five pairs of ventral ganglia are seen, the posterior larger than in the last stage. The posterior part of the abdomen lies at this stage still in the same plane as the rest of the body. The diverticula of the digestive tract are in the first appendages as in the last stage, the glands in the mandibles are still present, and the fifth pair of ventral ganglia still retain their invagination cavities.

The 'anlage' of the reproductive organs appears between the first and second pairs of walking legs in the mid-dorsal wall of the digestive tract, and is larger than in the last stage. In the anterior part of the body there seems to be formed a large heart carity.

After the next monlt (stage 7), Fig. XVII, we see an important change has taken place in the appendages. The third pair has almost completely disappeared, and only two small stumps indicate the point at which their appendage last appeared. The first and second pairs of appendages are unchanged in structure. I found one embryo of this age (7) having still the third pair of appendages, and for some reason the larva was quite appreciably larger than that given for this stage. Another pair of walking legs has been acquired-the third-and each of these has six segments.

The second pair of walking legs (the fifth pair of appendages) has now acquired its complete number of segments, eight, while the first pair retains its previous number of eight. The new segments which have appeared in the third pair of walking legs 
were interpolated at similar places to those of the preceding leg, viz. in the middle of the fourth and in between the fifth and sixth. There is an undeveloped pair of appendages at the posterior part of the larva, and the abdominal part of the body, instead of lying between them, as previously, has now mored dorsalwards, so that it projects from the posterior-dorsal part of the embryo. The first and second pairs of ventral ganglia (the first and second and the third in a true count) are in close contact or partially fused. The reproductive organ has much increased in size. In the region of the first pair of walking legs it extends through a few sections as two entirely separated parts, lying on each side of the middle line. In the region of the second pair of walking legs the two lateral parts unite into a single median structure which is almost as broad as the body, and the organ ends soon after this as a median, thickening on the mid-dorsal surface of the digestive tract. The glands of the mandibles have almost entirely disappeared.

At the next stage of development we have the formation of the seventh and last pair of appendages (stage 8), Fig. XVIII. There is a great increase in size, and an important change takes place in the second appendage. These lose their early larval structure and probably their first function, and now enter upon a new role. They are three-jointed and have lost the large terminal spine. The tip of the appendages is covered with many smaller spines, and sometimes I have seen one larger than the others, which presumably represents the large terminal claw of the preceding stage. The appendage is now three-jointed, having acquired an additional segment.

The first pair of appendages do not differ from the preceding stages. The third pair is still in an undeveloped condition, although somewhat larger than in the last stage. The fourth and fifth and sixth pairs have each eight segments, but the seventh pair, which has just been acquired, has only six segments. All of the walking legs have increased greatly in length, and each contains a long diverticulum from the digestive tract. Five pairs of ventral ganglia are seen, although the first and second are almost completely fused.

Sections show that the mid-gut sends out diverticula to the first, fourth, fifth, sixth, and seventh pairs of appendages and a 
pouch to the base of the rudimentary third pair. This pair of appendages is filled with embryonic mesoblast, and the ectoblast covering the appendage is thrown into a series of crenations beneath the cuticle, so that it would be much longer if extended, and is in condition to expand rapidly at the moulting period. This folding of the walls of the undeveloped appendage was seen also in all of the pairs of walking legs at the stage preceding their extension, and makes intelligible the great increase in length of the appendage when the next moult takes place. At the point of union of the gut-diverticulæ of the seventh appendage to the central digestive tube there is formed in the angle a small posterior pair of ventral ganglia. These were not seen in surface views, but lie above and behind the last pair of ganglia seen in the figure (XVIII), and belong to the rudimentary abdomen.

The 'anlage' of the reproductive organs is divided anteriorly into two parts, lying on each side of the dorsal side of the midgut, and run as far forwards as the base of the first pair of walking legs. Behind these divisions are united into a single mass in the region of the second pair of walking legs, and disappear at the anterior part of the third pair. There is a welldeveloped heart lying dorsal to these reproductive cells.

In the next stage we have a change which causes the larva to approximate much more nearly to the adult structure. The most important part of the change consists in the almost total loss of the first pair of appendages. See Figs. XIX and XX, Plate VI. Looking at the animal from the ventral surface we see no trace of this pair of appendages. Turning the animal over (XX) we find two projections at the anterior dorsal border where the first pair formerly arose. Each projection has two segments. A change has also taken place in the second pair, for these have now doubled the number of segments, and, except in size, have the adult structure. The third pair of appendages (XIX) has increased greatly in size, and now these form a pair of prominent projections on each side at the base of the proboscis. Each is bent almost at right angles back onto itself, and lies closely applied to the body in the space between the proboscis and the first pair of walking legs. Externally they do not show divisions into segments. The only point to note in the walking legs is that the fourth pair have now eight segments. The first three 
ganglia have completely telescoped, and this compound ganglia, it will be remembered, innervates the second, third and fourth pairs of appendages, as well as the proboscis. On the dorsal surface $(X X)$ is to be seen the two pairs of eyes equally dividing the periphery of the cupola-like projection of the dorsal surface. Sections do not give any additional facts worthy of note.

The last \&tage of larval life, or rather the last stages showing external traces of immaturity, is shown by Fig. XXI, stage 10, and although after this the larva undoubtedly undergoes several moults, accompanied by increase in size before becoming sexually mature, it did not seem necessary to figure such intermediate stages. The only change which has taken place in this stage XXI is in the appearance of segmentation of the third pair of appendages, and the number of the segments of this pair is that of the adult. The second pair of appendages has also increased in length, reaching to the distal end of the proboscis. All of the walking legs have the adult number of segments.

Having followed the larva through all these changes of growth, it may not be out of place to say a few words about the adult structures. A figure of the adult Tanystylum from the dorsal surface is shown by Fig. XXII. The compactness of the body of this species is exceptional and has been carried to such an extent that the bases of the walking legs are almost in contact, so that they radiate in all directions (except anteriorly) as from a central point. In most other Pycnogonids there is not so great a concentration of the body, and these undoubtedly come nearer to the ancestral form, and, moreover, in some of these simpler forms the rudimentary abdomen lies in the same plane as the body and behind the attachment of the posterior pair of legs. The figure for the anterior region of Phoxichilidium (Fig. XXIV) shows a form in which there is no such concentration. In Tanystylum, as seen in Fig. XXII, the abdomen has shifted far up on the back of the animal, and is separated by only a short space from the base of the prominence bearing the eyes. The adult still retains the rudiments of the first pair of appendages. These have a large basal segment and a smaller distal one covered with spines. Both males and females develop the ovigerous legs, and the males carry during the breeding season from one to three bunches of eggs on each of these appendages, as shown in Fig. XXIII. 
(This is not drawn to the same scale as XIV.) The bunches on each leg are entirely separated trom each other, while in Phoxichilidium (see Fig. XXIV) the bunches are larger than in the last (but with the eggs individually smaller), and are stuck to both of the ovigerous legs, which are thus bound firmly together by the sticky masses of eggs.

Before leaving the metamorphosis of Tanystylum, I wish to refer briefly to the development of the ventral ganglia. I had previously shown in Pallene that each ventral ganglion was formed by an invagination of the ectoblast, and I was led to infer a similar formation in Tanystylum, and by inference for all of the Pyenogonids. A study of the metamorphosis of Tanystylum has verified this beyond all doubt for that form, and I think it will be legitimate to extend this to the whole group.

The earliest stages of the development of the ventral organs in Tanystylum are shown in Fig. 52, Plate VIII, where the thickened ectoblast pushes in at two points on each side of the mid-ventral line. The nuclei of the cells of the invagination at this stage are scarcely, if at all, larger than those in the rest of the ventral ectoblast. A later stage in the formation of these ventral organs is shown by Fig. 54. It is taken from the third pair of ganglia. In this the cavities of invagination have closed, and the ganglion is now cut off from the ventral ectoblast. There are many ganglion-cells or nuclei forming the ganglion, and the nuclei in the cells bounding the cavities are larger, and oftener show karyokinetic figures than do the other nuclei of the ganglion. The last stage of development is shown by Fig. 53. Here the central cavity is almost obliterated on the right side, but on the left side the section cuts a little to one side of the central cavity, and only the cells of the wall appear, and two of these are seen in process of karyokinetic division. It is to be noted that the nuclei of the ventral organs at this stage are seen to approximate in size to those nuclei forming the substance of the ganglion, but stain more deeply. If we examine a little later stage, the central cavities of the ganglia have disappeared completely, the nuclei are all of the same size, and the only indication of the ventral organs is in the deeper staining of the cluster of nuclei at the spot in each ganglion where the cavity was last seen. Ultimately this difference also disappears. 
In the first part of this paper I was rather inclined to believe that the ventral organs had a phylogenetic significance, but still I must believe their interpretation to be an open question. The large size of the nuclei of these organs during their time of greatest activity in forming, and the subsequent merging of these nuclei (and cells) into ganglion nuclei (and cells), suggest that there may be no ancestral meaning to the process, but that there may be larval organs-something like neuroblasts-for the formation of ganglia. And it has been suggested to me that these may fall into the same category as the neuroblasts of Annelids, and may present, by analogy, an intermediate step in the formation of such cell-masses or teloblasts.

Another interesting problem might be discussed if there were space, viz. the appearance and subsequent loss of the third pair of appendages; and, again, the curious law discovered in the sequence of the walking legs, and its relation to the number of segments. When a pair appears for the first time, the number of segments is six; at the next moult the number increases to eight, by the interpolation of one and the division of one into two, and this method of increase is common to all of these appendages.

In thinking, too, over the remarkable series formed by the different species of Sea-Spiders, where, as Dohrn has shown, we can proceed from the simplest to the most complex, finding amongst living forms all intermediate stages, one finds a most suggestive field for speculation. Prof. E. B. Wilson has pointed out to me the great perfection of this series, and I have since been interested to find several other parallel cases in semiparasitic groups of animals, as, for instance, in the Copepods, in the Cuninas, in the Barnacles and in the Sponges. It would be interesting to discover the correlation, if any, between the persistence of a perfect series of animals of a group and semiparasitism.

[There are two other figures, $\mathrm{XXV}$ and $\mathrm{XXVI}$, which $\mathrm{I}$ have added to Plate VI, but these are not directly connected with the second part of this paper; nevertheless, as I only obtained them after the figures to the first part were printed, I have determined to add them now for the sake of completeness. The first figure is of the larva of Phoxichilidium at a time when it leaves the 
parent. This larval form shows certain differences from that of Tanystylum. In it the second and third pairs of legs are much longer, as the distal spine is prolonged out into a long threadlike continuation of the limb. In Tanystylum these spines were thick and short and adapted for crawling amongst the hydroids, while the long limbs of the larva of Phoxichilidium could hardly be used in this way, and suggest rather that they are used for catching to any objects they may come in contact with. The first pair of appendages are thicker in Phoxichilidium, with smaller claws, and the proboscis, instead of projecting forward between the first appendages, is only raised slightly above the level of the body at about its middle point. I have not obtained later stages of this larva, but the accounts of other species of this genus show that it becomes parasitic either inside the digestive tract of a hydroid or buried in its substance, and here it undergoes its metamorphosis until the adult structures are almost reached.

The other figure (XXVI) is of a young Pallene after it has left the parent, and this individual was found living freely amongst the Pennaria. The figure shows a ventral view, and the stage corresponds to one following that shown by Figs. VII and VIII of Plate IV. It shows the third pair of appendages beginning to develop, which, in Figs. VII and VIII of Plate IV, only appeared as two slight projections from the sides of the body. In the present case these appendages are folded across the breast-if the term be applicable to Pycnogonidsclosely adhering to it in the region between the base of the proboscis and the first pair of walking legs. The embryo has also fully developed its fourth pair of walking legs, which, it will be remembered, were in an undeveloped state in the previous stage.] 


\section{PART III.-THE STRUCTURE AND DEVELOPMENT OF THE EYES OF PYCNOGONIDS.}

In reaching a decision as to the systematic position of the Pycnogonids, I hoped to test the conclusions I had reached from a study of the embryology by taking another point of view. Fortunately a most interesting field opened in a consideration of the structure and development of the eyes. While enjoying the opportunities of the Marine Biological Laboratory I was enabled to procure and study an abundance of fresh material. The advantages of using such material is now so well known as to need only mention, and I am certain that I could not have obtained nearly so satisfactory results from preserved animals.

The results obtained from a study of the eyes have added, I believe, very much to the solution of the problem I had before me. Hoek and Dohrn gire the only figures of the Pycnogonid eyes that I have found, but the results are confessedly incomplete, due in the one case to poor preservation of material, and in the other to the difficulties of technique. Neither of these accounts will be of any service to us in our study of the eyes, and may be dismissed here. The subject will be treated in the following order:

1. The Anatomy of the Adult Eyes.

2. The Histology of the Adult Eyes.

3. The Development of the Eyes.

4. Comparison with the Arachnid Simple Eyes.

5. Inversion of the Pycnogonid Eye.

6. General Considerations of the Arachnid Eye.

\section{The Anatomy of the Adult Exes.}

The Sea-Spiders have in all four simple eyes, situated in the middle of the first (compound) segment of the body, on a raised, cupola-like projection. In some of the species the eyes are certainly degenerate, but in none are all traces of the eyes lost. The position of the eyes on the body can be best shown by reference to the figures. In Fig. XXII we see the dorsal surface of Tanystylum, and on this, in the so-called first segment, raised 
on a dorsal projection, lie the four eyes equally dividing the circumference. From the exterior each eye is seen surrounded by pigment, generally of a yellowish-black color. The eyes are extremely small and covered by thick chitin, rendering it exceedingly difficult to get at the eyes either for sections or for maceration.

Fig. XXIV shows a side view of the anterior end of Phoxichilidium. It shows the shape of the cupola-like projection bearing the eyes, two of which are seen on side view. The eyes of this species are much larger than the eyes of either of the other two Sea-Spiders, and for this reason were less difficult to manage, and the following account will apply to the eyes of Phoxichilidium, unless otherwise stated. "Alcoholic picro-sulphuric" solution gave by far the most satisfactory results. The body was cut across near to the eyes, and the portion containing the eyes fell immediately into the killing fluid. After thoroughly washing out the picric.acid the eyes were stained in hæmatoxylin and afterwards cut in paraffine.

We may start with a figure showing the whole eye removed from the body, as seen in Fig. 30, Plate VII. The figure is of an eye which had been sufficiently macerated to firee it from the surrounding tissue, removed in glycerine to a slide, and rolled around until the innermost part of the eye was turned upwards. The figure therefore shows the inner surface of the eye-that part nearest to the center of the cupola.

The pigment was, in handling, to some extent removed from this part of the surface, so that by focusing beneath this another layer of the eye could be seen. The figure shows the distribution of the optic nerve to the eye, which comes directly from the brain beneath the eye. The most important part of this fignre is the arrangement of the parts of the eye on each side of a median line-the raphe. This runs through almost the whole inner length of the eye as a somewhat irregular line from above downwards, and is formed by the elements of the visual part of the eye coming in contact from the two sides. Indeed, in this figure almost seventy-five pairs of these elements are seen arranged along each side of the raphe.

The optic nerve, before it reaches the eye, breaks up into several branches, and the branches enter the eye aloug its inner 
surface and along a line corresponding approximately to that of the raphe. The nerve branches disappear in the pigment covering the inner surface of the eye, and cannot be followed farther.

If we make a section in a horizontal plane through the cupola, so that all of the eyes are cut transversely to their longest diameter which runs from above downwards, we obtain a figure shown in 31. The four eyes are about equally distant from each other. In front of each the chitin is greatly thickened to form a lens; beneath this the corneal hypodermis is very much thickened; under the corneal hypodermis is a cup-shaped mass composed of two layers-1st, a light layer containing nuclei, and 2d, a layer of pigment surrounding the first. The entrance of the nerve is shown in some of the eyes at their inner, middle part. If we examine one of these eyes under a higher power of the microscope, we obtain such a figure as is shown in Fig. 32. The chitinous lens is well shown here, and the great increase of its thickness over the eje is very marked. The ectoderm of the body, the so-called hypodermis, also undergoes a great change in the region of the eye. The cells are much longer, have conspicnously large nuclei, and tapering away at their inner ends into fine processes which run out to the two sides of the eye. The whole arrangement of these corneal-hypodermal cellslentigen cells-is markedly bilateral, as seen in Fig. 32.

Immediately under the lentigen cells lies the middle layer of the eye. This is the retinal part of the eye, or that part sensitive to light. Immediately under the corneal hypodermis this middle layer of the eye shows a meshwork of fiber-like processes, which are probably interlacing and anastomosing nerve fibrils. Passing inwardly, there next follows a zone containing conspicuous nuclei and large vacuolated spaces. There next comes a zone which contains slightly stainable, rounded bodies slightly smaller than the nuclei. Lastly, in the bottom of this cup-shaped middle layer is a portion of the middle layer which stains more deeply than the rest of the middle layer, and radiating through this from the bottom of the cup outwards are several deeply stained (drawn black in the figure) rod-like bodies or bacilli. Corresponding somewhat to the intervals between the bacilli, the middle layer is indistinctly split up into 
bands running from without in, through what has been spoken of as the zones. These zones of the middle layer are not of course separated from each other, but pass insensibly into each other, and are only of use in describing the structure of the middle layer.

The nuclei found in the middle layer lie largely to the right and the left of the middle line of the eye, and through quite a wider zone of this layer. Thus they show to a large extent a bilateral arrangement. The inner layer is surrounded on its entire inner surface by a pigmented layer-the inner and pigmented layer of the eye. This layer is composed of pigment granules, both black and yellow, and it is impossible in such sections to resolve the layer into its constituent cells. The entrance of a part of the optic nerve is seen in the figure. It disappears in the pigment layer in the inner middle line, and cannot be traced farther, in sections, than the pigment layer.

Fig. 33 is a drawing of a longitudinal section through the same eye. It is therefore at right angles to the last figure and along the line of the raphe. This section, however, is not median through all its length, but at the onter part passes to one side of this line; at the inner part, however, it cuts approximately the middle line. But this slight obliquity is really advantageous to an understanding of the eye, as it passes more in the plane which the principal retinal elements follow. The three layers of the eye are clearly seen, although the distinction between the outer and middle layers is not so definitely marked as we saw in the cross-section, and is due here to the oblique plane of the section. Under the corneal hypodermis lies the large middle layer, in which we see the same structures as shown in the cross-section of the eye. The nuclei are conspicuous and numerous, and much more abundant here than in a section passing through the exact middle line. There are large vacuoles lying amongst the nuclei, but I have been unable to determine whether these are artefacts or natural to the eye. But I can scarcely believe them to be artificial products, as they seem to be constantly found on this part of the eye, and show no evidence of being due to tearing of the sections.

The layer of rounded bodies is not shown in the figure. The form of the retinal elements is better seen in this section than in the cross-section. At the inner part of the middle layer is a 
series of deeply stained rods-the bacilli, which occur regularly from the top to the bottom of the eye, and it was these which we saw in Fig. 30 arranged along each side of the middle line. These bacilli are continuous with the cell-walls of the retinal cells, which pass outwardly from the bacilli as far as the zone of nuclei. "The third and inner layer of the eye covers completely the middle layer as far forward as the cells of the corneal hypodermis, but its ending in the region of the hypodermis was not well shown in the section from which this figure was taken. This inner layer is composed of variously shaped cells containing much dark pigment, but the shapes of these cells can only be determined by maceration.

It may be well to explain here that the cells composing the middle layer correspond in number to the bacilli and cell boundaries shown in this figure, and that they form a series of inverted retinal elements, the length of which is almost as great as the depth of the middle layer; and, as we shall see later, there is a nucleus to each of these elements.

There remains a third plane in which I have cut sections of the eye, viz. that passing at right angles to the length of the retinal rods. A few sections of this series are shown in Figs. 34, 35 and 36. The first of these (34) is the second section from the inside, the first section having cut off a slice of pigment. We see the periphery surrounded by pigment, and in the center we see the arrangement of the outer ends of the retinal cells where they come in contact from the two sides. The raphe is here clearly seen to be formed by the contact of the bacilli of the two sides of the eye, and is formed as a zig-zag line by the interlocking of the bacillar ends of the retinal cells. Between the bacilli the granular protoplasm of the cell is seen, which runs almost to the tip, so that the bacilli are not formed at the inner ends of the cells, but along the side walls at the inner end. It is also not to be overlooked that only the superficial layer of retinal elements interlock at the surface, forming the raphe; and, while there are many other elements in the interior of the eye, these do not seem to come to the inner surface, but lie just beneath these superficial cells. At one point in Fig. 34, viz. in the lower left-hand portion, the section passes a little below the superficial bacilli, bringing to light the transversely cut ends of two of the interior retinal elements. 
A section of the eye somewhat deeper-that is, more outwardly - than the last is shown in Fig. 35. Along the middle line the central elements are cut transversely, showing the size in crosssection of the outer ends of these elements. On account of the bending of the outer retinal cells around the surface of the eye, they are cut now farther down than in Fig. 34, where their walls are thinner. Other elements lying between the central and superficial ones are cut somewhat obliquely, and the walls of some of these are seen to thicken, and to join the bacilli as they approach the middle line. In the lower part of the figure one sees that the bacilli show a double structure, so that one-half of the thickness belongs to one cell and the other half to the neighboring one; so that they are really double, but usually the separation into two parts is not seen, owing to the close fusion between the cells. This figure also shows the entrance of a part of the optic nerve, disappearing in the pigment layer.

Fig. 36 passes almost through the middle of the eye, but probably somewhat nearer to its inner half. The most interesting structures shown in the figure are the small rounded stainable bodies in the central elements. These lie in the outer ends of the cells found in the middle of the section. Around these the protoplasm seems absent or thinner, so that each has somietimes a halo about it. In other cells they are not seen, although they show a clear portion in the protoplasm, and probably the bodies are cut at a different level. The interlacing of the cells themselves in the central part of the eye should be noticed. They are longer from side to side, giving them in cross-section a lanceolate shape. At the sides of the section lie many scattered nuclei. Lastly, the nerve fiber is seen entering the eye along the middle line. The sections following this one as we pass to the outer part of the eye add little or nothing to what we have gained from the previous figures, and did not seem worth drawing. The vacuoles in the outer part of the inner layer are very conspicuons in some of these sections, and one also finds a few nuclei almost, or quite, in the middle line, but at all times they show a marked tendency to bilateral arrangement.

Such is the gross anatomy of the eye as gathered from sections, and a great many sections were made, prepared by many different methods, to obtain even this meagre information. As a 
check to the results obtained in Phoxichilidium, the less promising eyes of Pallene and Tanystylum were studied. It is not necessary for our purposes to give a full account of the structure of the eyes of these forms, as they showed in all essential points a close agreement with Phoxichilidium. To call attention to a few of the differences may not be out of place, so I have given two longitudinal sections of the eye of Pallene and Tanystylum.

Fig. 37 is a longitudinal section through the eye of Pallene empusa. The most noticeable difference, when compared with the eye of Phoxichilidium, is in the absence here of any wellmarked lens. The chitin is somewhat thicker over the eye than elsewhere, but not sufficiently so to form a definite lens. The three layers of the eye are clearly seen. The corneal hypodermis is not so well developed as in Phoxichilidium, and perhaps this is correlated with the non-development of the lens. The middle layer is essentially similar to that of Phoxichilidium, with its nuclei, vacuoles and rods. The bacilli are, however, relatively more abundant and closer together, and each bacillus is relatively longer. The inner pigmented layer is less well developed and forms a narrow yellowish zone around the inner part of the eye. Cross-sections add nothing to our knowledge, and sections at right angles to the raphe show that it, the raphe, is essentially as in Phoxichilidium.

In Tanystylum we find the same structures seen in the other two as shown in Fig. 38. The chitin over the eye is thicker than elsewhere, and forms a slightly developed lens, being intermediate in structure between Pallene and Phoxichilidium. The corneal hypodermis is much as in Pallene. The outer part of the middle layer shows few nuclei, which indicates it is near the median plane of the eye. The bacilli are fewer than either those of Pallene or Phoxicbilidium. Fig. 39 is a part of a section across the raphe, and, passing through it, shows the arrangement of the cells on the two sides. It was impossible to trace in these eyes the nerve fibers after they disappear in the pigment layer. They seem, however, to run around the sides of the eye, probably innervating the pigment cells in their course, and enter the middle layer from the sides and at its outer part beneath the corneal hypodermis. 


\section{Histology of the Eye.}

The following account of the histology is confined almost entirely to a description of the middle and inner layer of the eye of Phoxichilidium. The shape of the cells of the outer layer is sufficiently shown in Fig. 32. They are seen to be columnar, and have conspicuous nuclei in the middle part of the cell. The cells themselves show a bilateral arrangement, the smallest being on each side of the middle line and thence towards the sides, increase in length and breadth for a time, when they again begin to get smaller, passing into the ectoderm of the body at the point where the pigmented lajer touches the surface.

To obtain a knowledge of the middle and inner layers careful macerations were necessary, and as the results obtained by the different methods varied with the reagents used, it may be better to mention those found most useful. The easiest method to break up the eye into its constituent elements is maceration in a modification of Haller's fluid. The following proportions were used: Acetic acid (glacial) 5 parts, water 10 parts, glycerine 5 parts. The cupola bearing the eyes was cut off and quickly immersed in the fluid, remaining there from a half to an hour, washed in water, and teased out sometimes in water, sometimes in glycerine. The method has one disadvantage in that it causes the bacilli to swell up and become transparent, so that one may be misled-as I was at first-by the apparent absence of bacilli at the ends of the cells. The method has the great advantage in that it separates the individual elements completely from one another without breaking them up into pieces. Figs. 40, 41, 42, 44 and 45 were obtained in this way. A less successful reagent was that of sulphuric acid and sea-water. It has the advantage that the bacilli do not change their shape, but it does not easily separate the cells. Osmic acid was not very successful, probably on account of the difficulty of penetration.

After the macerated pieces were put under a cover-slip a little gentian violet was run under, which stained the cells and the nuclei, rendering them easier to study. If one is successful the middle layer breaks up into a great number of elements like those shown in Figs. 40, 41 and 42. Each of these elementscells - is a somewhat flattened body with one clear end-the inner -and a more protoplasmic middle portion containing a nucleus 
which stains deeply with gentian violet (40). Beyond this there is a slenderer region which continues outwardly (upwards in the figure) into a protoplasmic syncytium. This syncytium lies on the outer part of the middle layer, under the corneal hypodermis. The cell thus obtained shows no trace of the bacilli, but their absence is due to the macerating fluid, which causes them to swell at the sides of the cell.

Fig. $40 b$ was the most successful maceration obtained. Parts of three cells_retinal elements-are seen each passing at their outer ends into a common syncytial mass, as in the former case. The upper part of the figure shows a fine fibril running also into the fused protoplasmic part, and this fiber could be traced outwards into one of the nerve branches running to the eye, and undoubtedly represents the ultimate nerve fibril which passes to the retinal elements. The distribution of the nerve to the onter part of the middle layer, and the bacillus present at the inner ends of the retinal elements, show conclusively that the retina is "inverted"; so that light entering the eye must, before it can penetrate to the sensory end of the retinal elements - the bacillar end-pass through the layer of nerve fibrils and fused protoplasmic layer of the eye.

Fig. $41 a$ and $b$ shows to what an extent some, if not all, of the retinal elements are flattened. In $a$ the spatula-like end of the element is seen, and this shape is due to the swelling of the bacilli at the sides of the retinal cell. In $b$ the same element is shown as rolled over on its side, and is seen to be much narrower in this diameter than in the former. This accords fairly well with the shape of the elements seen in the section of Fig. 36, Plate VII.

In Fig. 42 three of the retinal elements are seen still in contact-two lying above a third, the inner end of which shows through the transparent ends of the others. Two have spatulashaped ends and the third is for most of its length broader than the others. Each has a nucleus nearer the outer half where the protoplasm swells out the cell, and beyond this the elements taper away to join, no doubt, in the syncytium at the outer part of the eye.

In Fig. 43 is a portion of the inner end of a retinal cell which was obtained by sulphuric acid and sea-water, and the figure is 
more highly magnified than in the preceding cases. The protoplasm runs down to the end of the cell, but on each side are the rod-like bodies. On the left side of this element is a piece of a rod of a neighboring cell; the bacilli being formed by the fusion of a pair of these rods of adjoining cells. Further, the end of the retinal element has been so twisted that one also gets a side view of the rod, showing it to be thinner through than broad. This preparation is unsatisfactory, in that it is broken off at the point where the cell-wall is continuous with the bacillus.

In Fig. 44 we see a copy of a part of the superficially lying retinal elements of the eye of Pallene. It shows how the cells lie side by side in the superficial part of the middle layer, but at one point one of the under cells comes out to the surface. The nuclei are placed in the upper (outer) part of each cell, and below these cells abut against those on the other side and form the raphe (not seen here). All of the middle layer cells seem to be very much alike, and although I have examined quite a number of macerations, I have never obtained any decided departure from those given above. On the other hand, I cannot deny that other cells may exist in this layer, for, on account of the small size of the eyes and the minute size of the retinal cells, it would be very easy to overlook any unimportant elements, but I think there can be no doubt but that what we have called the retinal elements form the greatest part of the middle layer.

If we next examine the cells of the inner layer-the pigment cells-we find them showing a very great diversity of shape. They are easily macerated apart by Haller's fluid (modified as above). A few of these cells are shown in Figs. $45 a, b, c, d$, illustrating the main varieties.

There seems to be a more or less definite distribution for these different kinds of cells, and we may refer them, I believe, to different parts of the posterior layer. Those pigment cells in the innermost part of the eye, lying over and at the sides of the raphe, are shown in Fig. $45 a$. These are short, somewhat cylindrical cells, about as high as wide, and fitting tightly into one another. Ten of them form the mass in this figure, and in some of them the nucleus can be seen, and in all the cell boundaries made out. The cells found over the sides of the eye show great differences in size and shape, as seen in Fig. $45 b, c$ and $d$. 
In $d$ the cells are drawn out at one side, becoming longer in one diameter, and this process seems continuous into a nerve fibril, though the process could only be traced for a short distance, and I have not succeeded in tracing it actually into such a fibril. In $c$ two cells are shown which have fused together at the base, and from the point of union a process runs ont which presumably is continuous into a nerve fibril. I think one must be impressed by the close similarity between two such cells shown in $c$ and the similarly arranged retinal cells of Fig. 40. Now, although I have no actual proof that the cells $d$ lie nearer to the cells $a$, and that the cells $c$ are farther around to the sides of the eye, yet from what I have seen I think it exceedingly probable that in passing from the innermost cells of the pigment layer to the outermost (those nearest the hypodermis) we go through a series of changes as shown by $a, d, c$. Finally, in Fig. $45, b$, there is seen a long, slightly pigmented cell resembling much in shape a retinal element. I cannot affirm positively that this cell belongs to the pigment layer, but it seems exceedingly probable that it does. If so we find quite a good series connecting the most modified pigment cell on the one hand with the retinal elements on the other; and, further, each of those pigment cells seems to connect by quite a large process with a nerve fibril. The insportant bearing of this arrangement, etc., will be discussed in another place.

\section{The Development of the Eyes of Tanystrludr.}

Instead of beginning with the earliest stages of the eye, which are the most difficult to understand clearly, let us start at the other end, when the eye has not quite reached maturity, and work thence backwards.

Fig. 51, Plate VIII, is from a longitudinal section through the posterior eye of a larva which has just acquired four pairs of walking legs. (See Fig. XVIII, Plate V.) In this the ectoderm has, in hardening, separated somewhat from its chitinous covering, but there is no special thickening of the chitin over the eye to form a lens. The three layers of the eye which were found in the adult are here easily recognized. The outer layer, which is formed but slightly modified hypodermal cells, contains large nuclei, which are arranged in a single layer. The 
arrangement of the elements of the middle layer is not well shown in the figure, but other sections show that they are essentially as in the adult, and that small rods, bacilli, are developed along the sides of the inner ends. The eye also shows in other sections a distinct raphe. The inner layer is not so much pigmented as in the adult. The essential interest of this figure lies in the relationship it reveals between the first, the outer, and the second, the middle, layers of the eye. If we follow from above downwards the layer of corneal hypodermis, we find that when it reaches the lower angle of the eye it suddenly turns inwards and becomes directly continuous into the middle layer of the eye, and that the large nuclei of the outer can be traced continuously into the nuclei of the middle layer at this point.

This figure does not show the relationship between the pigment layer and the hypodermis, but others do, and it may be stated that just below the eye the pigment layer becomes continuous into the hypodermis, and at the upper part of the eye, as seen in this figure, the middle and inner layers are in close contact. We may interpret this condition of the eye by referring it to an invagination of the ectoderm, the opening, if it exists, being at the lower corner of the middle layer; that the two walls of the invagination are of different thicknesses, etc., the middle layer being one and the pigment layer the other; and, finally, the whole invagination being pushed over to one side -dorsalwards. I think this interpretation of the conditions is not forced, and is the explanation of the conditions shown not only by this but by other figures.

Figs. 49 and 50 are from a larva having three pairs of walking legs. (See Fig. XVII, Plate V.) These two figures belong to the same series, and are neighboring sections of one of the posterior eyes. The animal is about ready to moult, so that we find two distinct chitinous coats, the one closely adhering the other over the latter and not directly connected to it. Fig. 49 is somewhat to one side of the middle line, especially in the upper part of the eye, but near to it in the lower part. The corneal-hypodermal cells at the lower corner of the eye pass into the cells of the middle layer. The outlines of the cells are better seen than in the previous section, and small rod-like bodies are seen at their inner ends. The middle layer is smaller than in the pre- 
ceding older stage. A narrow zone of pigment cells forms the inner layer of the eye, and at the lower corner of the eye it passes directly into the hypodermis below the eye, while at the upper corner of the eye the pigment layer is never found intimately connected with the hypodermis, but is in close contact with the middle layer of the eye. Fig. 50 cuts the upper part of the eye in the middle line, but not so much so the lower. In the upper corner of the middle layer there lies a cell which is shorter and broader than the retinal cells farther down, and very often the second cell from the top shows a somewhat similar difference in shape. In fact, these two cells seem to be present in all the larval eyes, and the meaning of this we shall see later.

Fig. 48 shows the posterior eye of a still younger larva. (See Fig. XVI, Plate V.) Here again we find practically the same conditions as in the preceding figures, but the eye is smaller. The corneal hypodermis passes at the lower corner into the middle layer of the eye. The pigment zone behind the eye is narrow, and the third layer is seen to continue into the hypodermis below the eye. At this place the cells of the hypodermis are very distinctly seen passing into the pigment layer of the eye. The middle layer is separated very distinctly from the corneal hypodermis by an elongated cavity, probably caused by shrinkage.

Between this eye and the next earlier stage there is quite a difference in size and structure. This next stage is shown in Fig. 47, which is from a larva having a single pair of walking legs. (See Fig. XV, Plate V.) Both posterior eyes are shown in this figure (47). They are not, as in all older eyes, raised above the general surface of the body. Each eye is still seen to be three-layered, though this is not so apparent as in older stages. Both the outer and the inner layers are quite narrow. The middle layer is seen to be formed of two quite large clear cells with very large nuclei. These form by far the most conspicuous part of the eye in cross-section, but I have not determined definitely whether there are only these two cells, as seen in crosssection, or whether there are a few more present. There is, it must be confessed, not much evidence of invagination of the eye at this stage, and for this reason it seemed better to begin with older stages, which could be easily interpreted as such. How- 
ever, in the eye on the left side of the figure (47), the continuation of the corneal hypodermis with the middle layer is seen, and in the right eye the pigment layer is intimately connected with the hypodermis on the outer side of the eye ; so that the arrangement is essentially as in older stages. I could not determine definitely as to the number of cells forming the pigment layer, but in cross-section one can discover not more than two nuclei, so that the number must be exceedingly small. Besides the pair of eyes seen in this figure, there is an anterior pair resembling the above both in structure and size. There is one difference shown in the sections of the anterior eyes, viz. that there is a thickening of hypodermal cells on each side just beyond the outer corner of the eyes, but of this I shall speak later. Moreover, the anterior eyes are nearer together than the posterior pair.

Fig. 46 is from a larva without any walking legs, at an age shown by Fig. XIV, Plate V. The larva has but a single pair of eyes, which correspond to the anterior of the two pairs of older larvæ. We find the eyes have essentially the same structure as in the one last described, but are much nearer together than those of the last figure (a posterior pair). Each is composed of three layers. Of these the middle is much larger, and is com. posed of two large transparent cells with large nuclei. The continuity of the corneal hypodermis with the middle layer was not clearly made out, nor that of the pigment layer with the ectoderm below the eye; but I think we may fairly push our interpretation even to this, but on account of the extreme smallness of the eye and the difficulty of making very thin sections, such connections would not be readily discovered. The posterior layer of the eye seems to be formed of but a single large flattened, pigmented cell, showing a clear nucleus, but it cannot be affirmed with anything like certainty that this is the only cell.

On each side of the anterior eyes the ectoderm, as shown in Fig. 46 , is a greatly thickened mass, indeed forming two bodies about the size of the two eyes themselves. I am at a loss to interpret these thickenings. At first I believed they might be connected with the sudden increase in the size of the eye, and the very great change in size in the eye between stages XV and XVI of Plate $\mathrm{V}$ might seem to support such an hypothesis. But, on the other hand, the posterior eyes also increase greatly in size at the same 
time, and these have the ectoblast very slightly thicker at the edge of the eye. Possibly these may represent rudimentary eyes which were placed on each side of the first pair, or else have shifted position from some other place; at any rate, they are of interest and very constant in position, and furnish very little ground for speculation.

The structure of the eye of the Pantopod-larva was described in Part I. This description is correct, I believe, as far as it goes, but at the time I had little knowledge of the adult eye, and hence overlooked an extremely narrow layer of ectoblast between the two large cells and the chitin. I have since re-examined the eye of this larva, and can assert that in some sections this layer could be made out, and in others a thin membrane-like body separated the clear cells (middle layer) from the chitin, and this, presumably, is the same ectoblast. Unfortunately, the section from which the figure of Plate I was made had only a very narrow ectoderm layer, and was overlooked. We may affirm, then, that the eye at all stages of development is a three-layered structure.

\section{Comparisun with the Arachnid Simple Exes.}

We are now in a position to make, if possible, a practical application of the preceding. Does a study of the structure and development of the Pycnogonid eye throw any light upon the relationship of the Sea-Spiders to other groups? I think there can be no doubt of this, and that it furnishes a most satisfactory verification of the relationship pointed out in the preceding sections.

It seems absolutely impossible to bring the eyes into the same category with the eyes of the Annelids, which is a decided gain for our position, and it is par excellence an Arthropod eye, and even more, as I hope to show it must be referred to a particular group of Arthropods-the Arachnids. The absence of any very close resemblance to the eyes of Annelids would not be in itself * a final argument against Dohrn's position, inasmuch as the eyes may have been much modified during the transition from Annelid to Pycnogonid; but this can scarcely be the case, for the eyes seem to show traces of degeneration in many, if not in all (as shown, perhaps most strikingly, by the large vacuoles, and 
the slight development of lens in some forms), and this could not be accounted for had the group first acquired an eye so different from the Annelids, and afterward, without change of habitat, degenerated. Further, we find a remarkable agreement with the Arachnid eye, and it seems much more probable that this (even alone, but we can consider it now in connection with many other peculiarities, both in structure and development, common to the two groups) has a phylogenetic meaning, and forces one to abandon the theory advanced by Dohrn.

First 1 must state that the principal papers which I have used in the following comparison are those by Lankaster and Bourne on the Simple Eyes of Limulus, Locy on the Development of the Spider's Eye, and Mark on the same subject, Parker on the Eyes of Scorpions, and Laurie on the Development of the Eye of the Scorpion. Of the more speculative papers of Patten and Watase I shall speak separately.

The adult eyes of the Sea-Spiders show three distinct layersthe corneal hypodermis, the retinal or middle layer, and the posterior or pigment layer. It has been demonstrated beyond doubt that the Arachnid median eyes are composed of three layers, and, further, that these are more apparent in the embryo than in the adult Arachnid. Further, the arrangement of the layers is essentially the same, for we find a corneal hypodermis, a middle sensory layer, and a posterior narrow layer.

The middle layer in the embryo Spiders (where the eyes have been studied in most detail) contains at the inner ends of the retinal cells clear (stainable) rod-like bodies, or bacilli, which seem to be identical with the similar bacilli of Pycnogonids. The bacilli in the Pycnogonids are at the inner ends of the cellsin other words, the retina is inverted-and in the embryo Spiders we find that similar rods are also at the inner ends of the cellsthat is, the retinal elements are here also inverted. A secondary shifting, or change, takes place in the Spider's eyes, so that in - the adult the eyes and retina become righted; but how this later change comes about is at present, I believe, unknown.

Lastly, the eyes of the Pycnogonids are formed by a process of invagination of the same nature as the invagination in the Arachnids (Locy, Parker, Laurie, Brooks). This invagination, instead of being an open cup (as in Insects), turns to one side 
and comes to lie under another part of the hypodermis, which forms the onter layer of the eye, and the wall of the invaginated tissue lying outmost forms the middle layer, and the inner the inner layer of the adult eye. The invagination of the cells to form the eye does not take place all at once in the eye of the Sea-Spiders, but is a gradual process, so that a few cells at a time are added to the eye, and this is connected with the presence of a small, free larval form having the beginnings of the eyes. In the Arachnids, on the other hand, the process of invagination is more marked, in that all the cells are invaginated at once. These similarities in development and adult structure, it seems to me, point unmistakably to a community of descent between the Pycnogonids and the Arachnids, and further, they point to the same conclusion which we reached in studying the embryology of the group, that the Sea-Spiders show in their adult structures close resemblances to the embryos of the Arachnids, inasmuch as the inversion of the eye of the Pycnogonid agrees with the inversion of the embryo Spider, and the well-defined three-layered condition of the latter in the embryo is seen fully developed in the eye of the adult Pycnogonids.

\section{Inversion of the Eye.}

The early inversion of the eye of the Spiders has been noticed by Locy, and Mark has extended this discovery to the solution of certain theoretical problems. The latter suggested that the process of invagination of the Spider's eye repeats the method by which such an eye arose, that is to say, if we start with a simple cup-shaped invagination and suppose the walls on one side to have increased greatly, so that they ultimately filled up the central cavity, rolling over into this cavity, the inversion of the eye was explained. The opposite wall of the cup remaining thin and developing pigment, became the inner layer of the eye, and the general hypodermis of the body formed the secreting cells of the lens or the outer layer. Patten has suggested that the Arachnid eye is but a later stage of development of that seen in the Insect eye. The walls of the optic cup turn in from the two sides, the elements at the sides becoming first horizontal, then turning into the cavity of the vesicle, the retinal cells at the bottom of the vesicle forming a posterior (inner) layer to the 
eye. Patten's suggestion was at the time, I think, little more than a suggestion of a possibility, and no structures in the Arachnid eye were given to support it.

Mark, on the other hand, has complicated his hypothesis by certain additions, both of which I believe one would, à priori, rather reject, if possible. First, that the one-sided development he supposes to have taken place to have been the result of a change of position in the lens, so that part of the eye was placed to better advantage than the rest, a supposition not founded on any facts, and it seems to me highly improbable. Secondly, the inverted elements of the embryo right themselves (as they are so found in the adult) by a complete.change in the parts of each element, so that the rods which are at first secreted at one end of the cell-the inner-subsequently are formed at the opposite end of the element-the outer-and that the nerve fibrils were also transferred from one end of the cell to the other. To be sure we do not yet know how the eye does right itself, yet it seems most improbable it has done so by such an unusual method, and it would be much easier to believe that the elements shift around so that their inner ends become the outer.

I have examined carefully the inverted eye of the Pycnogonids to see if it would throw any light upon the early inversion of the eyes of Arachnids. In the first place, I am inclined to believe that this inversion of the Spider's eye cannot be explained as a purely embryonic phenomenon. From what has been given in the preceding sections, I am ready to believe that this inversion of the embryo Spider's eye is to be explained as a phylogenetic process, and that the adult Pycnogonid's eye represents approximately the condition of the eye of the ancestral Arachnid (or, at any rate, the ancestral Spider).

Let us now see if there is anything in the Pycnogonid eye to determine whether this primitive inversion was caused by a onesided development of the eye, as Mark has assumed (for Spiders), or whether we have any evidence pointing in other directions. I have been much impressed by the bilateral arrangement of the eye in the Pycnogonids, and it has seemed to me probable that this might give a clue to the solution we are in need of. The corneal hypodermal cells show a marked bilateral structure in the arrangement of the cells on each side of the middle line. 
The middle layer (and this is more to the point) shows a strong bilateral arrangement-first, in respect to the nuclei which lie largely on the two sides, and, secondly, in the arrangement of the retinal elements to the right and left of a median raphe. The third layer has a bilateral arrangement, the cells along the middle being different from those along the sides of the eye, and those at the sides approximating in structure to the retinal elements.

It does not seem to me that it is possible to interpret this bilaterality on Mark's hypothesis, because it furnishes not the slightest reason why an eye so derived should show a two-sided arrangement, nor is it likely to be explained as a secondary arrangement.

On the other hand, if we assume the inversion to have arisen by a turning in of two sides of an optic cup-a process already shown in the Insects' simple eyes-we see clearly why the eye should present so perfectly a bilateral plan. To explain this more in detail, we may start with a simple invagination, forming a thick-walled cup with nerve fibers entering the inner ends of the cells. The early stages of development of Insects' simple eyes show such a condition. Next, the lips of the invagination touch and fuse, forming an almost continuous layer over the eye, giving the corneal hypodermis. The bilateral arrangements of this layer in the Pycnogonids may be the expression of this union from the two sides. At the same time that this occurs, the more horizontally-lying retinal elements in the upper part turn into the cavity of the cup, so that their morphologically outer ends now come to point inwards. The nerve fibers which ran up to the back part of the eye continue to do so, and, running from their point of contact around the onter wall of the cup, supply the elements with fibrils. This is practically the condition of the simple eyes of Insects. Such an eye may be said to be (imperfectly) three-layered at this stage, as we may now count the partially inverted elements as a middle layer. The elements lying at the base of the cup are in a disadvantageous position for vision, being covered by a sensory layer (the inverted fibers) lying between them and the light. So these elements of the bottom of the cup and at the sides degenerate and become a pigment layer at the back of the eye. Now we have reached the type of eye found in the Sea-Spiders. 
The evidence that the eyes of the Sea-Spiders have evolved along some such line as this is found in the structure of the eye as existing to-day. The median raphe of the middle layer indicates the points of contact between the retinal elements from the two sides. These, as they became inverted, came into contact in the middle line. The bilateral arrangement of the nuclei follows almost as a necessity of this two-sided inversion. These would be crowded together when the retinal elements turn in, and few or none along the middle line. Patten shows on the outer ends of the retinal elements of Insect eyes a layer of what he calls "secondary nuclei," which, so far as I can judge, are identical with the round stainable bodies found at the inner ends of the inverted elements of the Pycnogonid eye. One sees at once that by the inversion of the lateral elements of the cup the bodies must be found in exactly the same position as they are found in the Pycnogonid eye.

If further evidence were needed to prove the two-sided inversion, it would, I think, be amply found in the conditions existing in the pigment layer of the eye. The cells immediately at the back (at the base of the cup) are cylindrical cells, such as would result from a shortening of the retinal elements. If one draws a diagram of the process I have sketched, it becomes evident that as we progress around the sides of the eye the pigment cells must pass insensibly into the retinal cells; and such, indeed, we found previously to be the case. Thus the retinal cells here have not suffered so great a change as those at the back of the eye; but, developing pigment, they furnish a dark background for the retinal cells, but still retain largely their ancestral shape. Finally, the large nerve process running from these pigment cells is explained by their ancestral function as fibrils to the retinal elements.

To sum up, I believe all the layers of the Pycnogonid eye give abundant evidence that the eye has developed by the turning in of two sides of a primitive optic vesicle, and that the simple eyes of Insects furnish all the intermediate stages, both in development and adult structure, between a simple cup-like invagination and the three-layered condition of the Pycnogonid eye. ${ }^{1}$

1 This and several other facts (as multipolar delamination, etc.) point perhaps to a genetic relationship of Insects to Arachnids, but I cannot go into these comparisons at present. 
I am inclined to push this a step further and attempt to show that the median Arachnid eyes have developed along a similar path, and this must be a necessary corollary to the position to which I have assigned the Pycnogonids, and believe, as I have before said, that the inversion of the Spider's eye is its Pycnogonid stage of evolution and the righting of it a secondary and later change. I also believe there is no evidence that in the evolution of the Spider's eye a change of position in the lens has taken place.

\section{General Consideration of the Simple Eyes.}

Before leaving the subject there are two points to which I must refer-the meaning of the invagination of Arachnid (and Pycnogonid) eye, and the explanation of the grouping together of the retinal cells into bundles or retinulæ.

It will be at once seen, with respect to the first point, that I have placed more faith in the evidence furnished by the adult eye of the Pycnogonids and Spiders than in that given by the ontogeny of those eyes, while Mark has utilized the ontogeny as furnishing a basis for his considerations.

It seems to me that the development of the eye, as we find it in the Pycnogonids, is entirely an ontogenetic process, $i$.e., it represents here an abbreviated condition. Instead of recapitulating all the early stages, forming first a cup, then turning in the walls, it performs the whole process at one time and thus complicates the matter. In the Pycnogonids the presence of the eyes in all the larval stages, presumably functional in each, must have changed the original process to a very great extent. ${ }^{1}$ Yet through all these stages we have been able to recognize the three-layered condition of the eyes. We must believe, from what has been said of the growth of the eye, that in the Pycnogonids the invagination (of the Arachnid type) has been retarded, so that, one end of the invagination being formed, the inturned and inverted cells have functioned as larval eyes, and as the animal increased in size the invagination kept pace, adding more and more cells to the layers of the eye, so that all of the stages had presumably functional eyes, and at the same time the larva retained the original type of Arachnid invagination.

${ }^{1}$ We do not know whether the ancestral Arachnids had free-living larve or not. 
It may not be out of place to say a few words about the formation of bundles of elements in the eyes of many Arachnids, as the preceding may have some bearing on the question. In several of the Arachnid median eyes the retinal elements group themselves into bundles of a varying number of cells - the retinulæ. Wratase has advanced the idea that these bundles represent each an invagination-a pit-of ectoderm, and represent the process of formation of the eye elements-ommatidia. He homologizes the retinulæ of the simple eyes with the retinulæ of the compound eye; in the latter he also believes they represent ancestral invaginations. I do not care to carry my comparisons into the compound eye, but shall speak only of the simple eyes, in which, I think, there is not sufficient evidence that these bundles each represent an invagination.

It seems most probable that these groups of cells forming retinulæ represent secondary changes in the eye. If the Arachnid eyes have, as I believe, come along some such lines as have been just sketched, then it is evident that the eyes have several times undergone profound changes of which the median Arachnid eye to-day is the outcome. The Insects' eyes show no such complicated groupings of cells as do the Arachnid eyes. The Pycnogonid eyes show no trace of such bundles of cells. And by no means do all the Arachnid eyes show this, as I have satisfied myself in the Spiders. So, unless one had preconceived ideas to apply to the simple eyes, I see no reason for supposing such a combination of cells to represent an invagination. On such a theory the clear central part of the bundles-the center being formed by the union of the inner parts of the cells forming the grouprepresents the original chitin secretion of the hypodermal cells. I can find no evidence to support this assumption, although I have examined carefully, both by sections and macerations, the retinula-bundles of sereral Arachnids. The clear central partthe rhabdome-is not a secretion from a cell, but only a clear protoplasmic (?) portion of it, and is included in the general wall of the cell. Nor is there any evidence that it is of a chitinous nature, for to micro-chemical reagents it acts entirely differently. Further, an apparently similar substance is formed at the sides of part of the retinal elements of both Insects and Pycnogonids, and although in the former the cells are in the proper position, 
this clear stainable portion is at the sides and not at the ends, for a thick protoplasm lies between the rods. Finally, we find similar transparent and perhaps more solid parts of the retinal elements of other eyes belonging to quite different groups, as in the Ascidians and in the Mollusks (see Pecten), and certainly in the latter group no one will imagine them chitinous or any homologue of chitin.

\section{LIST OF WOKKS REFERRED TO.}

1. Balfour. Notes on the Development of the Araneina. Quart. Journ. Micr. Sci., vol. XX, 1880.

2. Balfour. Elements of Embryology. 1880.

3. Clans. Crustaceen-Systems. Wien, 1876.

4. Dohrn, Ant. Neue Untersuchungen iiber Pycnogoniden. Mitth. a. d. Zool. Stat. Neapel, Band I, 1879.

5. Dohrn, Ant. Die Pantopoden des Golfes von Neapel. Fauna und Flora des Golfes von Neapel. Band III, 1881.

6. Hatcheck. Beiträge zur Entwicklungsgeschichte der Lepidopteren. Jena, Zeit. Naturwiss., No. 11, $18 \% \%$.

\%. Heider, K. Ueber die Anlage der Keimblïtter von Hydrophilus piceus. Abh. d. K. Preuss. Akad. d. Wiss. Berlin, 1885.

8. Müller, Fritz. Für Darwin. Leipzig, 1864.

9. Metschnikoff, E. Entwicklungsgeschichte des Chelifer. Zeit. f. wiss. Zool., XXI, 1871.

10. Schimkewitsch. Zur Entwicklungsgeschichte der Araneen. Zool. Anz., VII, 1884.

11. Schinkewitsch. Étude sur le développement des Araignées. Archiv de Biologie, 6, $188 \%$.

12. Sedgwick, A. A Monograph of the Development of Peripatus Capensis. Stud. Morph. Lab., Camb., IV, Pt. I, 1888.

13. Semper. Ueber Pycnogonida und ihre in Hydroiden schmarotzenden Larven-formen. Arb. a. d. Zool. Zoot. Inst. Würzburg, 1, 1874.

14. Wheeler. The Embryology of Blatta Germanica and Doryphora Decemlineata. Jour. Morph., III, iss9.

15. Wilson, E. B. The Pycnogonida of New England and Adjacent Waters. U. S. Commissioner's Report, Pt. VI, 1878. 
REFERENCE LETTERS FOR PLA'TES.

$B$. Brain.

$D$. Mid-gut, mesenteron.

$D^{I}, D^{I I}, D^{I I I}, D^{I V}$, etc. Diverticula of mid-gut.

$E$. Ectoblast.

N. Entoblast.

M. Mesoblast.

$P$. Periphery of blastoderm.

$S$. Schizocoels.

$V^{1-7}$. Ventral ganglia $1-\%$.

$H$. Heart.

L. Legs.

O. Opening ventral organs.

$C$. Central cavity of segmenting egg.

\section{DESCRIPTION OF PLATES.}

\section{Plate I.}

Figure 1. Section of segmented egg and membranes of Pallene empusa.

FIG. 2. Section of another egg of Pallene at same stage to show central cavity $C$.

Fig. 3. Section through upper pole of egg of Pallene. First formation of blastoderm.

FIQ. 4. Section through upper pole of egg of Pallene. Later stage than last. Inner cells-entoblast-are present.

FrG. 5. Section through egg of Pallene. Later stage than last. Cap of cells-blastoderm-covers more of egg than in last.

FiG. 6. Section through periphery of blastoderm, at $P$ of Fig. 5 .

FIG. \%. Section in same region as last.

FIG. 8. Section of segmenting egg of Tanystylum orbiculare, to show pyramidal shape of cells.

FiG. 9. Section of egg of Tanystylum, to show process of multipolar delamination.

Fig. 10. Same, with delaminated entoblast.

FIG. 11. Section of segmenting egg of Phoxichilidium maxillare.

FIG. 12. Same, to show degeneration of endoderm.

FIG. 13. Cross-section of the Pantopod-larva of Tanystylum orbiculare.

FIG. 14. Circumœsophageal ring of same. 
Fig. 15. Eyes of same.

Fig. 16. Ventral organs of same. Early stage of third pair of ganglia.

Plate II.-Sections of Pallene empusa.

FIG. 1\%. Longitudinal section through stomodæum of young embryo. First origin of mesoblast at $M$.

Frg. 18. Cross-section through stomodæum of older stage. See line 18, Fig. I, Plate IV.

FIG. 19. Section anterior to last. See line 19, Fig. I, Plate IV.

Fig. 20. Section anterior to Fig. 19. See line 20, Fig. I, Plate IV.

Frg. 21. Cross-section of ventral organs. See line 21, Fig. I, Plate IV.

FIG. 22. Cross-section of ventral organs at stage III.

FIG. 23. Cross-section of ventral organs at stage V.

FIG. 24. Cross-section of ventral organs at stage VI.

FIG. 25. Cross-section of embryo at stage III.

Fig. 26. Cross-section through brain and second pair of ventral ganglia of stage III.

FIG. 2\%. Cross-section of embryo in the plane of a pair of legs, about stage VI.

FrG. 28. Cross-section of embryo in the plane between a pair of walking legs, about stage VI.

Fig. 29. Cross-section through the rudimentary abdomen and the body of an embryo, stages VII-VIII.

Plate III.

$A-J$, Pallene empusa. $a-c$, Phoxichilidium maxillare. $d-f$, Tanystylum orbiculare.

FrG. A. Segmenting egg, side view, 2-celled stage.

FIG. B. Segmenting egg, seen from above, 4-celled stage.

FIG. C. Segmenting egg, seen from above, 8-celled stage.

FIG. D. Segmenting egg, seen from below, 8-celled stage.

FrG. E. Segmenting egg, side view, 16-celled stage.

FIG. F. Segmenting egg, surface views of micromeres, 16-celled stage.

FIG. G. Segmenting egg, side view, 16 macromeres, 8 micromeres.

Fra. H. Segmenting egg, side view, 24 macromeres, 16 micromeres.

Fra. J. Segmented egg, lower pole, base of pyramidal cells shows at surface. 
FIG. a. Phoxichilidium, 2-celled stage.

Fig. b. Phoxichilidium, 4-celled stage.

Fig. c. Phoxichilidium, 8-celled stage.

Fig. d. Tanystylum orbiculare, 2-celled stage.

FIG. e. Tanystylum orbiculare, 4-celled stage.

FIG. f. Tanystylum orbiculare, 32 (?)-celled stage.

\section{Plate IV. I-VIII, Pallene. IX, Tanystylum.}

Fig. I. Surface view of young embryo, to show anterior region.

FIG. II. Surface view of ventral region of same.

FIG. III. Ventral view of embryo with four pairs ventral ganglia, first and second separate.

Fig. IV. Dorsal view of embryo about same age (a little older perhaps) as last.

FIg. V. Ventral view of embryo. First and second ventral ganglia have fused.

FIG. VI. Side view of embryo, showing rudimentary abdomen behind as a continuation of the body and in same plane as the body.

Fig. VII. Ventral view of embryo at the age when it leaves the parent. Fourth pair of walking legs seen behind; third pair of appendages beginning just in front of first pair of walking legs.

FIG. VIII. Dorsal view of last, to show brain and four eye spots. In both VII and VIII only the proximal ends of the legs are shown.

FIG. IX. The Pantopod-larva (Protonymphon of Hoek) of Tanystylum orbiculare.

Plate V.-Metamorphosis of Tanystylum. Zeiss 4 A $\frac{1}{2}$.

Fig. X, stage 2. Young larva after leaving parent and after first(?) moult. Ventral view.

FIG. XI, stage 2. Dorsal view of last.

FIG. XII, stage 3. Ventral view.

FIG. XIII, stage 4. Ventral view, showing three pairs of ventral ganglia, the first really composed of two.

FIG. XIV, stage 4. Dorsal view of last. One pair of eyes-the anterior.

FIG. XV, stage 5. Ventral view with first pair of walking legs, each with six segments.

FIG. XVI, stage 6. Ventral view with two pairs walking legs, the first with eight segments, the second with six.

FIG. XVII, stage \%. Ventral view with three pairs walking legs, 
the first with eight segments, the second with eight, the third with six.

FIG. XVIII, stage 8. Ventral view with four pairs walking legs, the first with eight segments, the second with eight, the third with eight, the fourth with six.

\section{Piate VI.-Larvæ and Adult of Tanystylum. Larva of} Phoxichilidium. Larva of Pallene.

FIG. XIX, stage 9. Tanystylum. Ventral view. Showing renewed growth of third pair of appendages. Zeiss $4 \mathrm{~A} \frac{1}{2}$.

FIG. XX, stage 9. Dorsal view of last. Showing rudiments of first appendages. Zeiss $4 \mathrm{~A} \mathfrak{z}$.

Frg. XXI, stage 10. 'Tanystylum. Ventral view. Showing segmentation of third appendages, and fusion of first, second and third ventral ganglia. Zeiss $4 \mathrm{~A} \frac{1}{2}$.

FIG. XXII. Adult Tanystylum. Dorsal view. Proportionately less magnified.

FIG. XXIII. Ovigerous leg and eggs of Tanystylum. Zeiss $2 \mathrm{~A} \frac{1}{2}$.

Frg. XXIV. Adult Phoxichilidium. Side view of male with eggs. $\times 30$.

FIg. XXV. Pantopod-larva of Phoxichilidium.

FIg. XXVI. Larval Pallene. Ventral view. Showing the undeveloped third pair of appendages.

\section{Plate VII.-Eyes of Phoxichilidium, 30-36. Pallene, 37.} Tanystrudu, 38-39. Zeiss 4 D $\frac{2}{3}$, except Fig. 31.

FIG. 30. Eye of Phoxichilidinm, viewed on the inner side, from a macerated preparation. Showing distribution of nerve to eye and bilateral arrangement of elements along the raphe.

FIG. 31. Section across cupola, containing the eyes which are cut into "cross sections" (horizontal with reference to body).

Frg. 32. Cross-section of eye as in 31 , but more magnified.

Frg. 33. Longitudinal section of eye, parallel to raphe.

FIG. 34. Section in plane at right angles to other two. Showing bacillar ends of the elements of the retina, forming by their union the raphe.

Frg. 35. Section in same plane, but further out than last.

FIG. 36. Section in same plane, but nearer the center of the eye.

FrG. 3\%. Longitudinal section of eye of Pallene.

FIG. 38. Longitudinal section of eye of 'Tanystylum.

Frc. 39. Inner view of cells forming raphe of Tanystylum. 
Plate Vili.-Macerations of Eye of Phoxichilidium. Development of Eye of Tanystylum and Section of Ganglia OF SAME, ETC.

Fig. 40. Retinal elements of eye of Phoxichilidium obtained by maceration in Haller's fluid.

FIG. 41. Others of same.

FIG. 42. Collection of three retinal elements, from maceration.

FIG. 43. End of cell showing bacilli, from a maceration in sulphuric acid and sea-water.

FIG. 44. Retinal cells of outer surface of middle layer of Pallene.

FIG. 45. Pigment cells of inner layer of Phoxichilidium.

FIG. 46. Eye of Tanystylum-larva. Longitudinal section of anterior and only pair. Stage 4. Zeiss $4 \mathrm{~F} \frac{2}{3}$.

FIG. 4\%. Same of older larva. From posterior pair. Stage 5.

FIG. 48. Same of one posterior eye of older larva. Stage 6.

FIG. 49. Same of one posterior eye of older larva. Stage $\%$

FIG. 50. Section in same series as last.

FIG. 51. Same of older larva. Stage 8. Zeiss $4 \mathrm{~F} \frac{2}{3}$.

FIG. 52. Cross-section through posterior part of body of larval Tanystylum, showing beginning of a pair of ganglia, etc. Zeiss $4 \mathrm{D} \frac{2}{3}$.

FIG. 53. Pair of ganglia with ventral organs disappearing.

FIG. 54. Pair of ganglia with cavities of ventral organs. Zeiss 4 D $\frac{2}{3}$. 


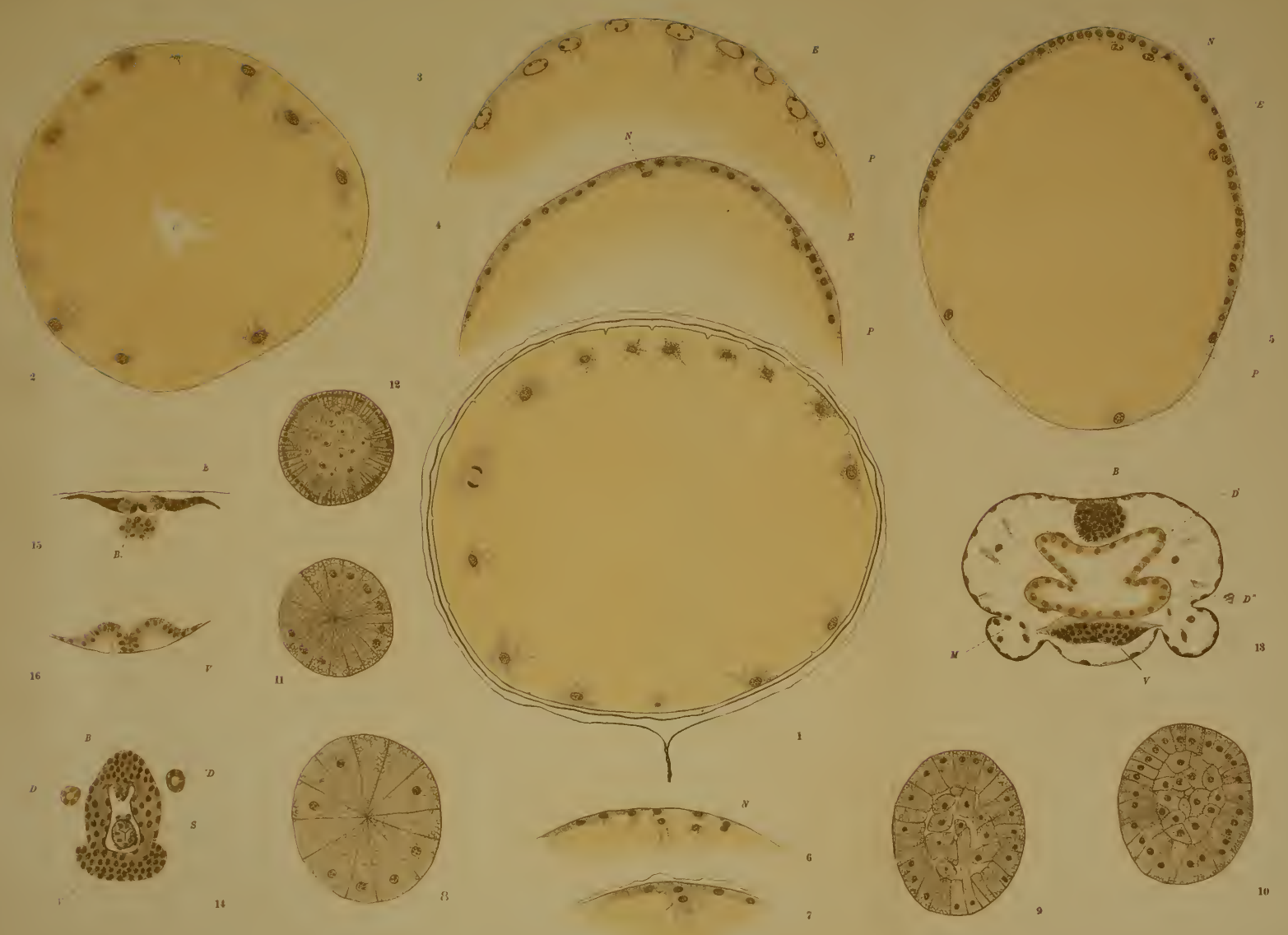




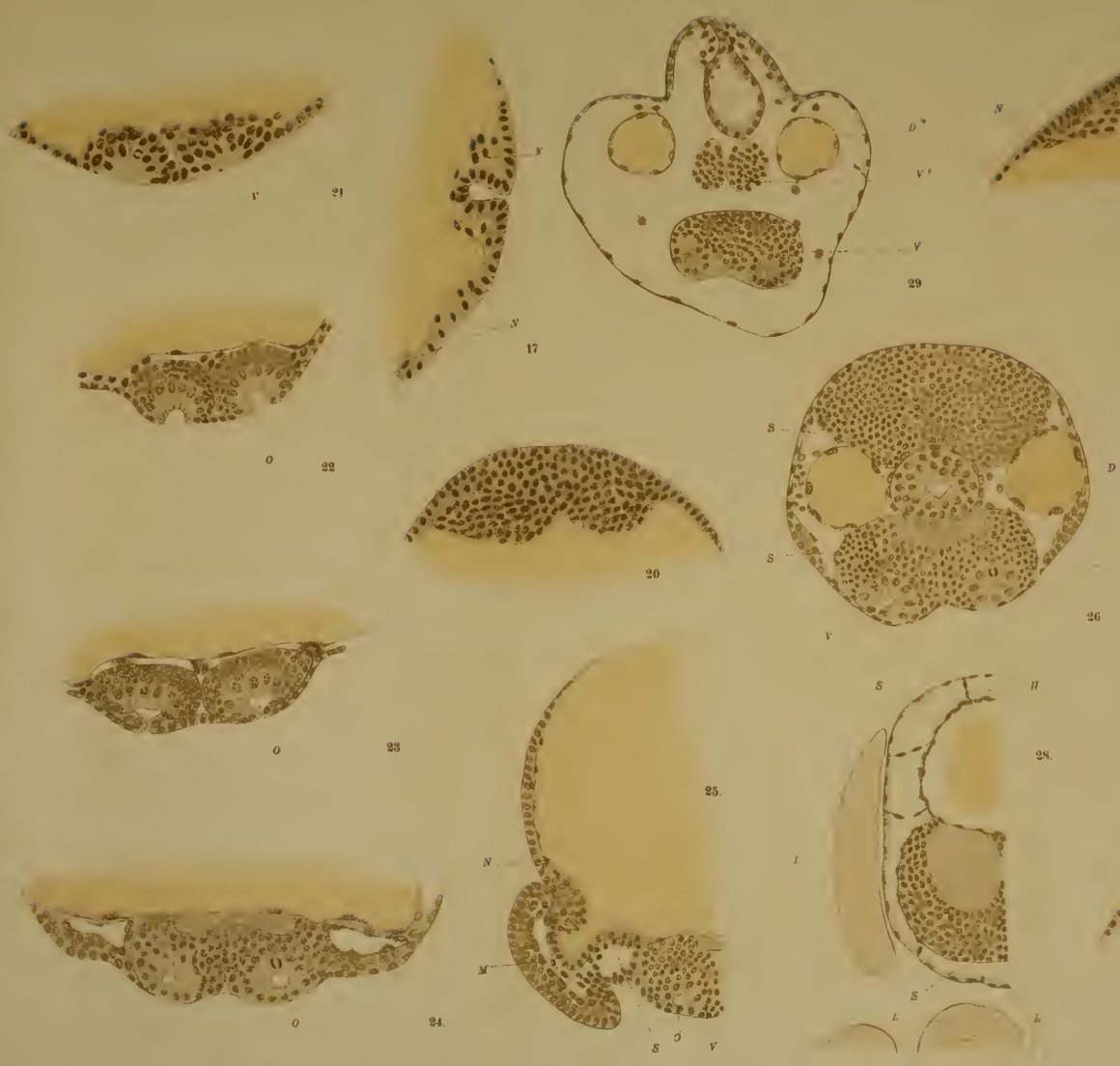

25.

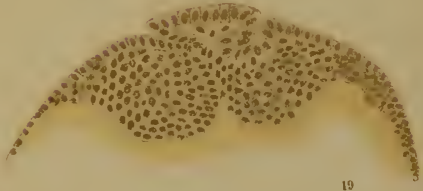




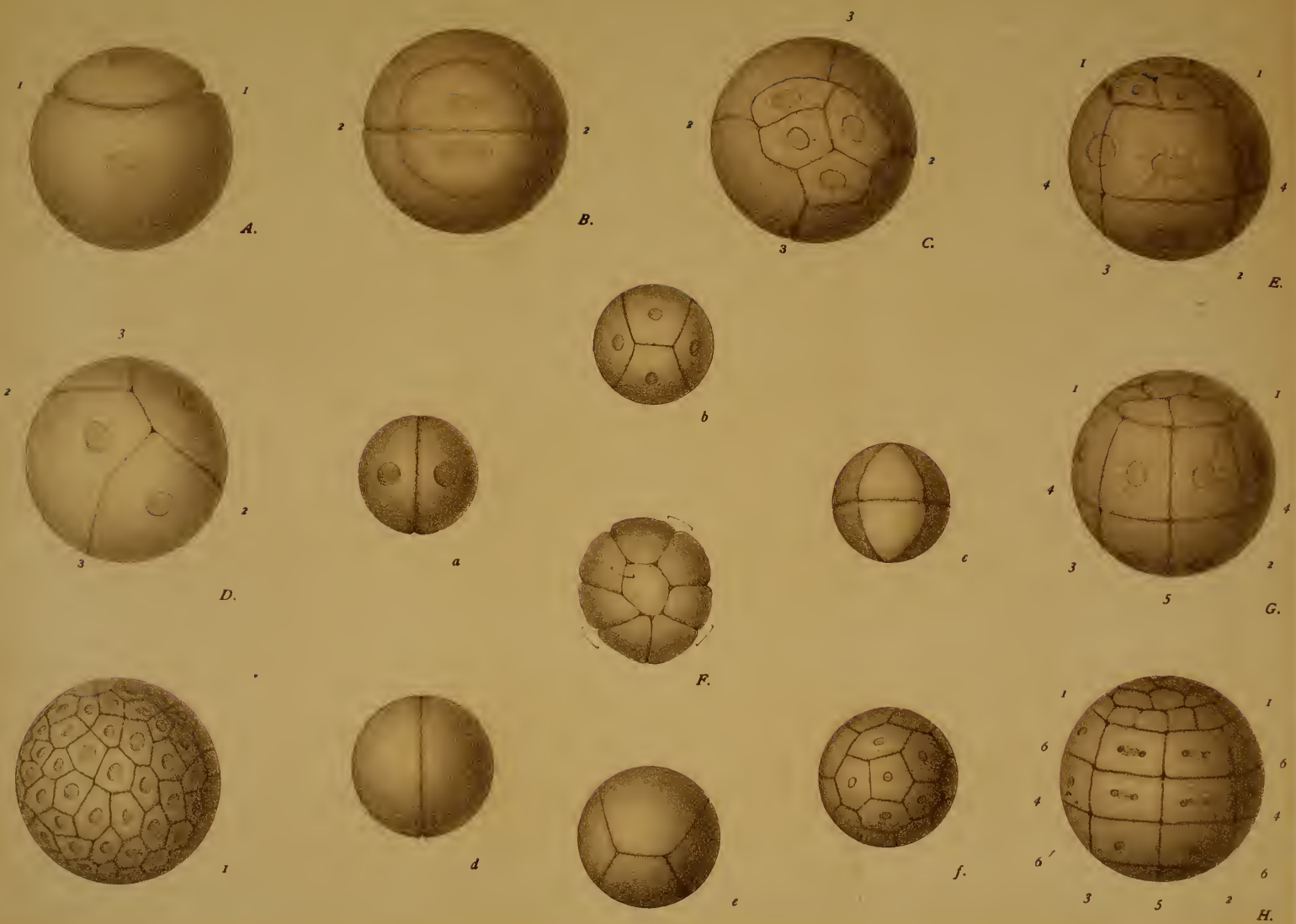


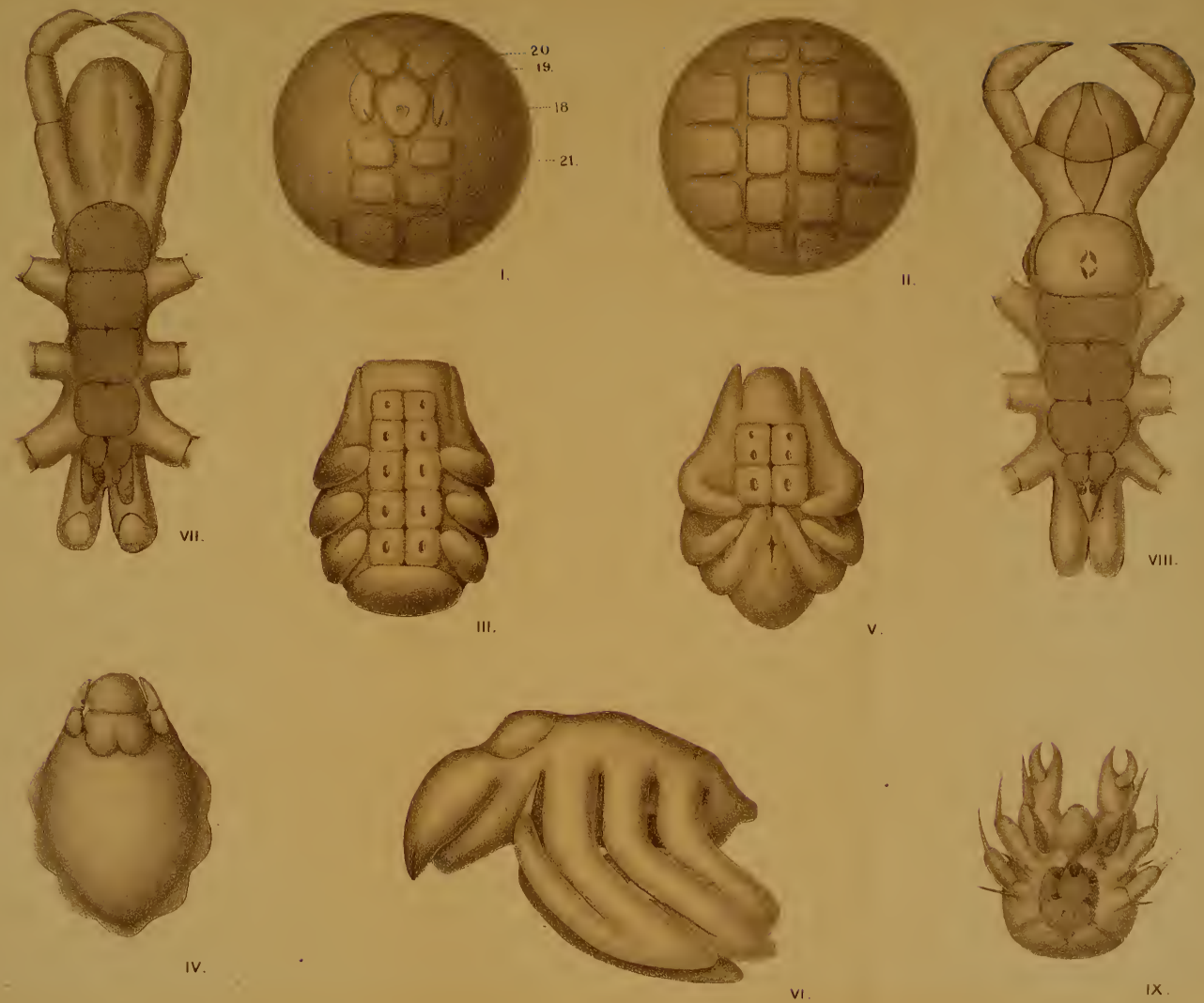



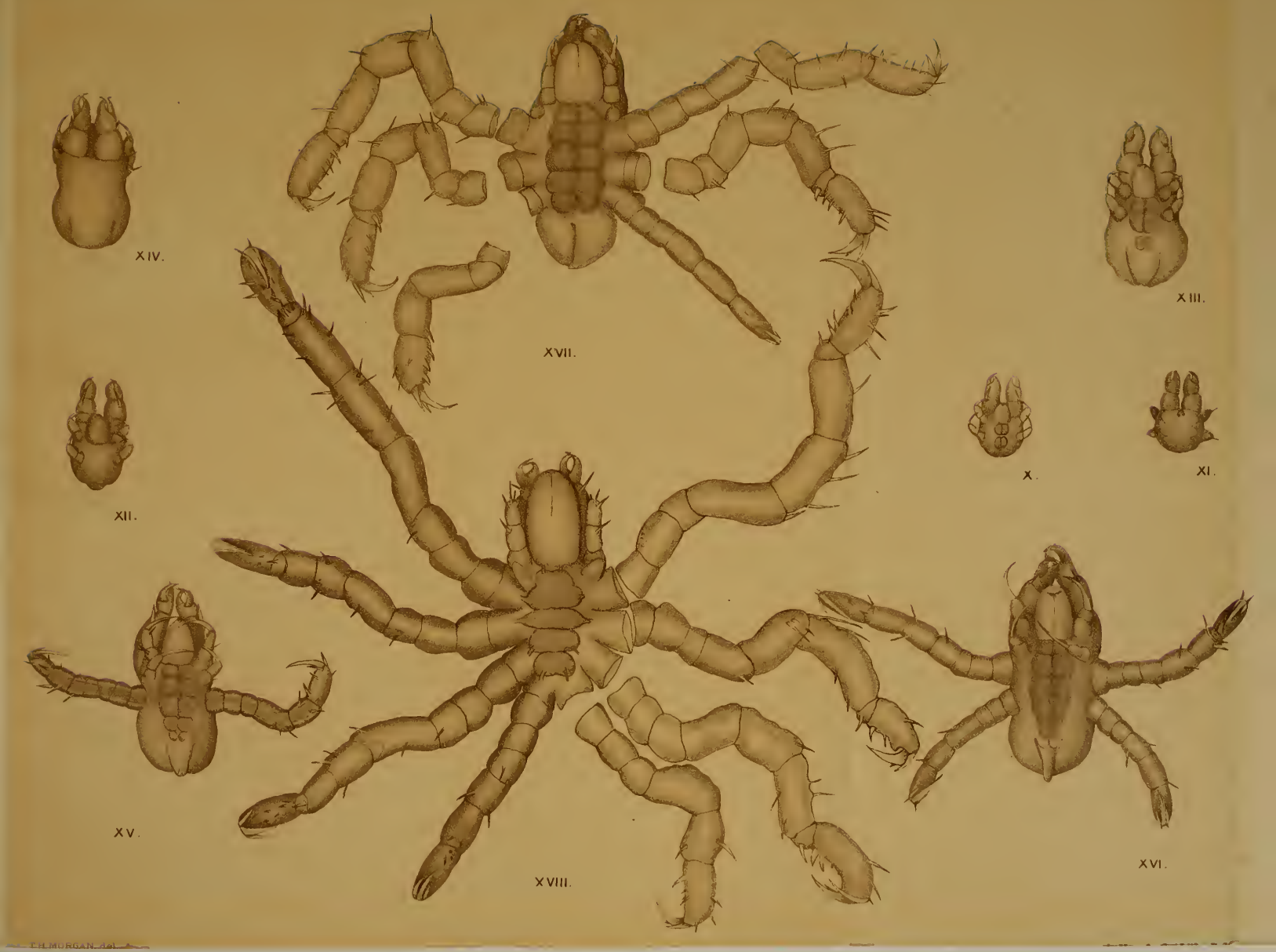




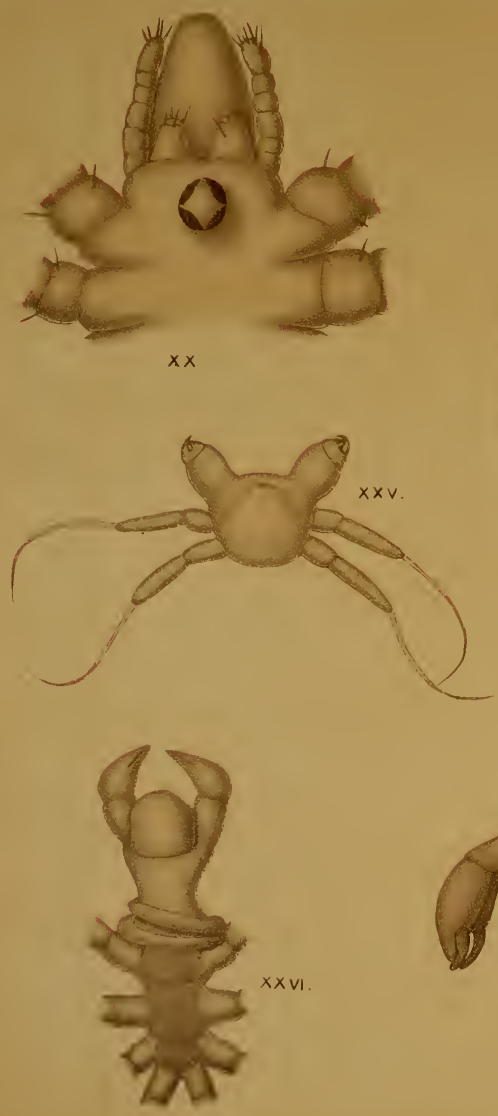
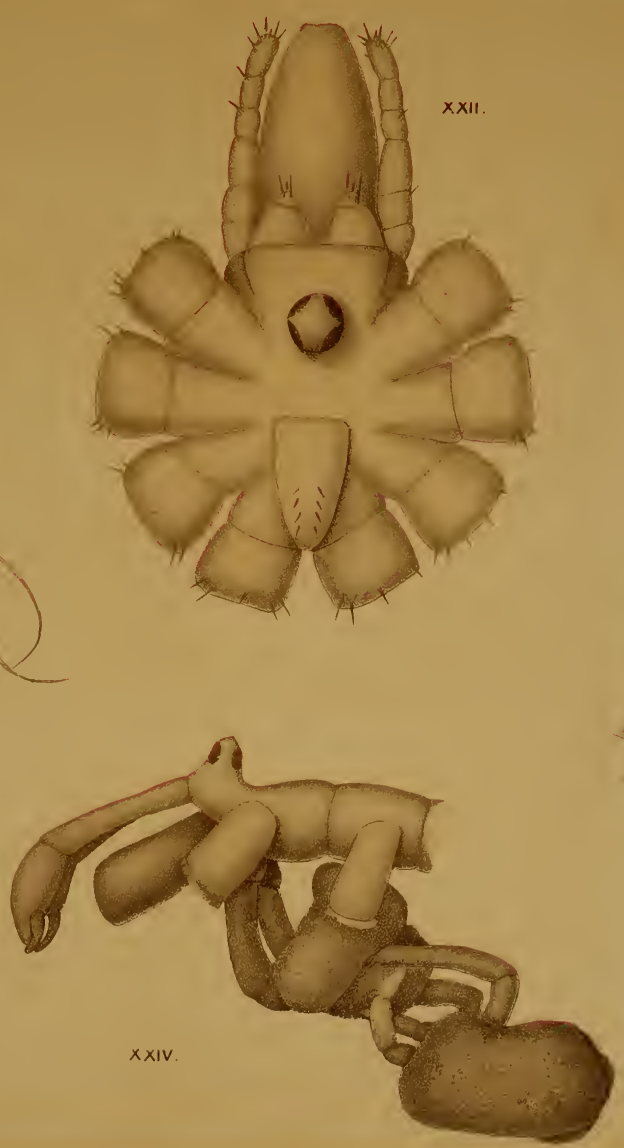
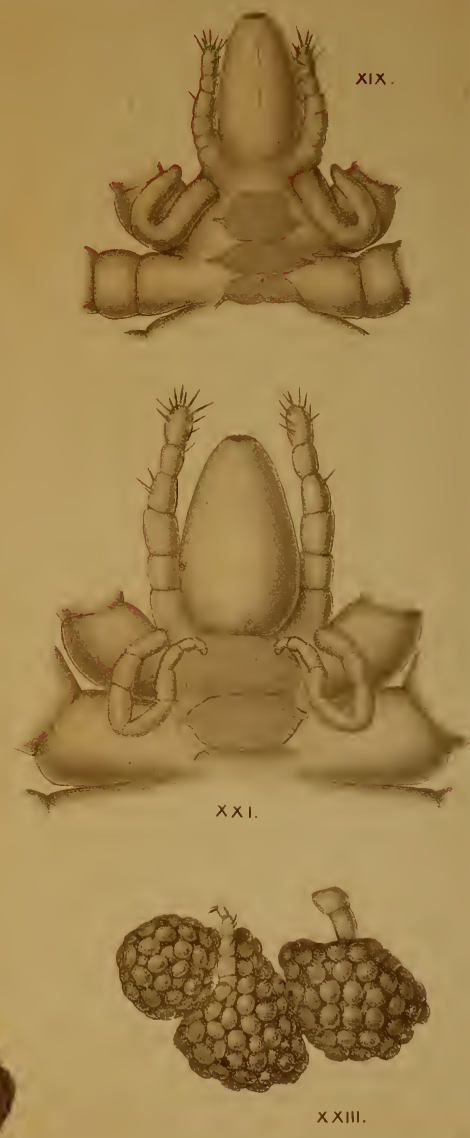


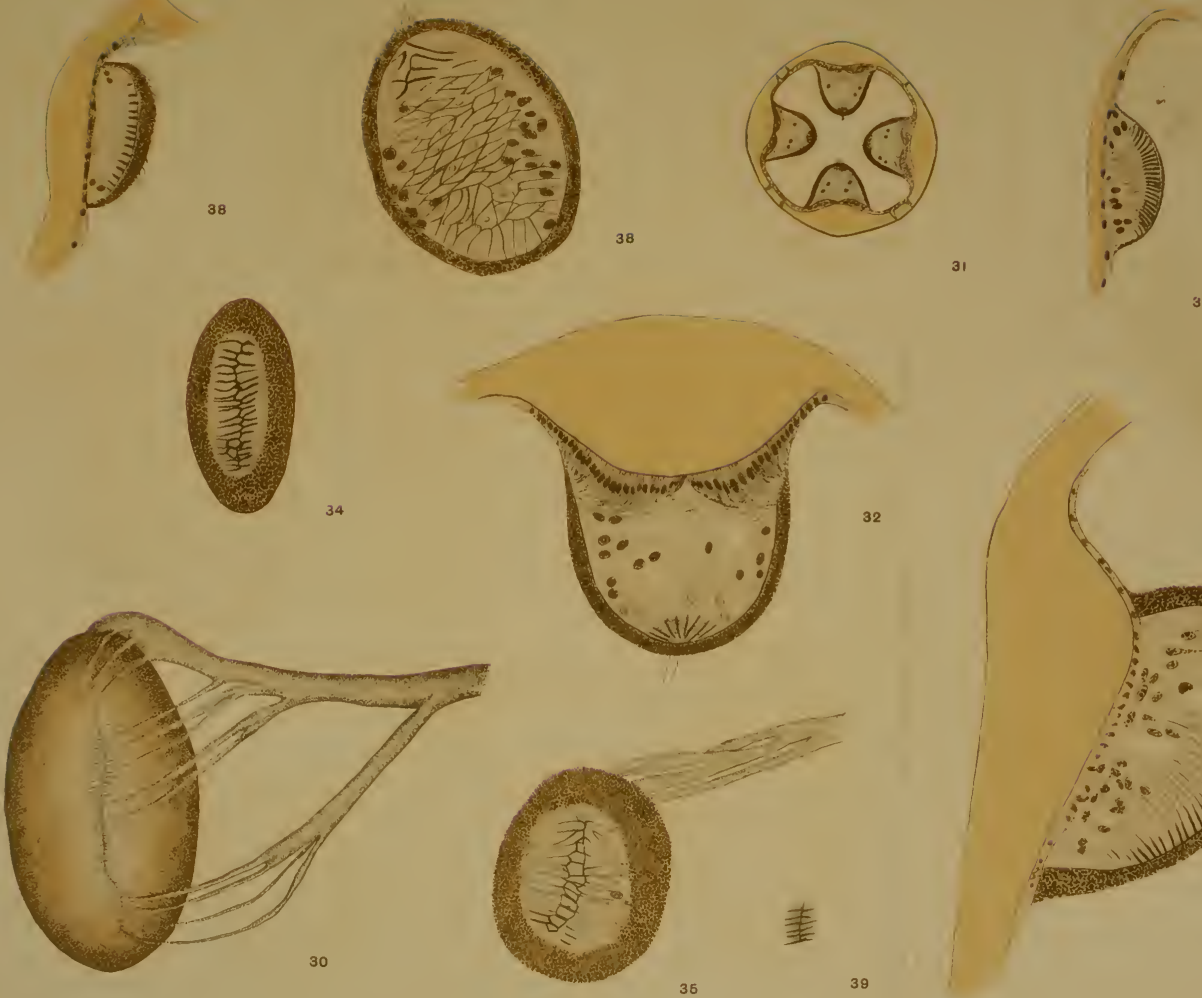

a)

37

34

35 


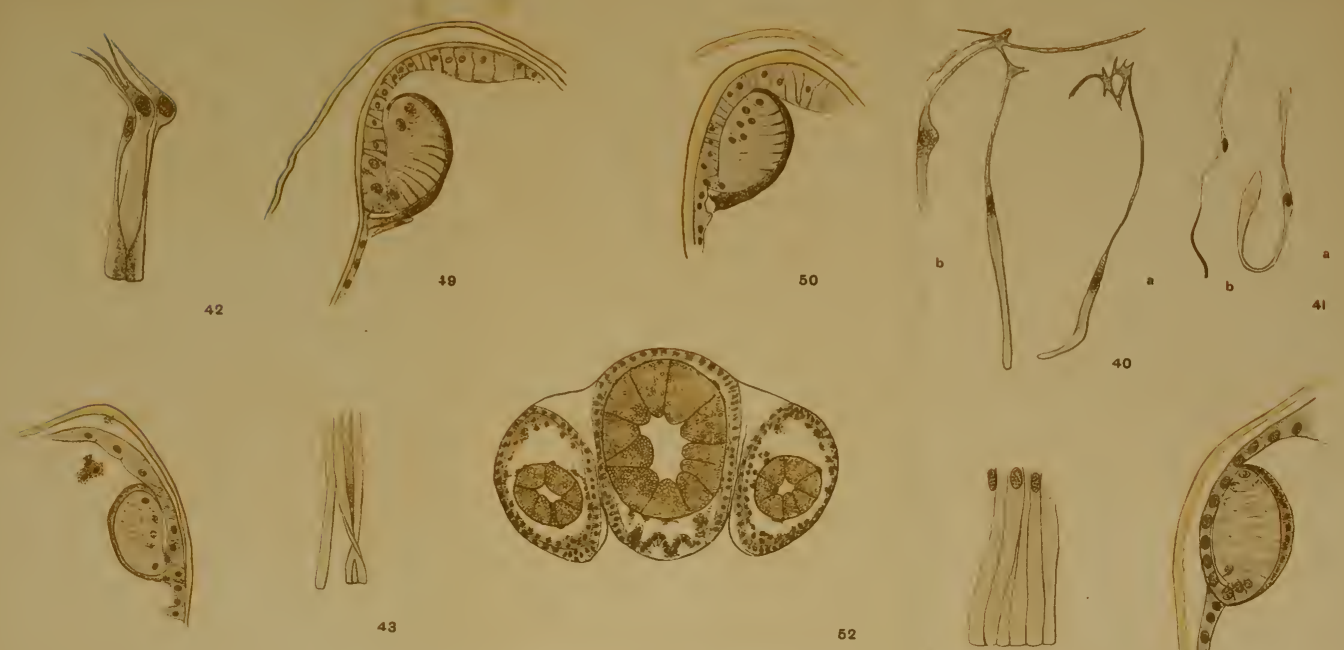

48

ज...
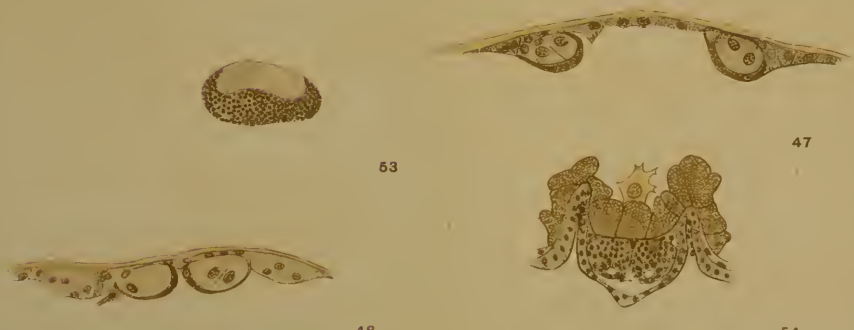

48

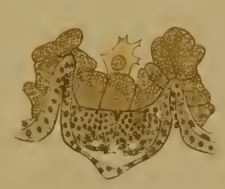

47

54
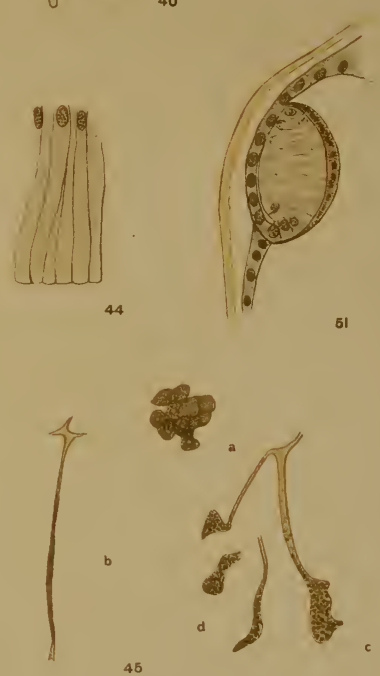


